\title{
Reflexiones acerca de la enseñanza del español como lengua de segunda adquisición a personas adultas hablantes de tamazight
}

$M^{\mathrm{a}}$ Ángeles Sánchez Suárez

Jefa de Estudios del Centro de Educación de Personas Adultas

"La palabra es un signo. En esta afirmación está todo el mundo de acuerdo. pero lo difícil es precisar de qué es signo. Me gustaría demostrar que es signo de un saber plegado, tácito. Representa algo que ya sabemos, pero que no conocemos. El significado real, psicológico, concreto de una palabra, el que posee un sujeto. es algo que el sujeto sabe pero que no conoce. Podriamos definirlo como el conjunto de información que permite explicar los usos que hace de esa palabra, los estrictos y los laxos. los serios y los lúdicos. La inteligencia realiza poderosas sintesis de información que la memoria guarda. Pues bien, la palabra nos permite acceder y aprovechar ese complejo tesoro. Se parece más a una caña de pescar que a un cuadro. Gracias a ella recuperamos información adunada en la memoria".

José Antonio Marina. "La selva del lenguaje". Colección Argumentos. Editorial Anagrama

"Cuando se trata de formular un perfil de los pueblos amerindios, las más de las veces el retrato resultante es el de la carencia; carencia de recursos económicos y materiales, carencia de condiciones de higiene y sanitarias adecuadas, carencia de educación ( $y$ por tanto deficitarios culturalmente), e incluso carencia idiomática ("ni siquiera hablan español" o "lo que hablan no es un idioma, es un dialecto"). De este modo la carencia aparece como uno de los rasgos principales de la indianeidad.

Aparece asi una ecuación que se repite constantemente: pueblos indigenas = pueblos indigentes. De ahí que atender la especificidad cultural de los pueblos indigenas se transforme en combate a su pobreza. Ser "indio" es ser pobre; al dejar de ser pobre se deja de ser "indio", e igualmente dejar de ser "indio" es un indicador de que se está dejando de ser pobre. Así. en función de esa insostenible ecuación ideológica, la indispensable lucha contra la pobreza se convierte en una legítima justificación para acabar con las culturas indigenas". 
La reflexión acerca de nuestra práctica docente es quizá uno de los aspectos más descuidados de la labor del educador y, sin embargo, fundamental. Es necesario que sepamos dónde estamos instalados a nivel ideológico y educativo, ya que sería realmente desmoralizador que nuestra práctica nos estuviera conduciendo a objetivos no planificados y ni siquiera deseados por nosotros mismos. Puesto que esta "praxis" educativa no es neutra, analicemos a dónde nos conduce reaimente.

Que la sociedad en la que vivimos es multicultural y por lo tanto lo es también la escuela en todos sus niveles educativos, incluido el de "Educación de Personas Adultas", como fiel reflejo de la misma y que la educación debe tender a proporcionar igualdad de oportunidades a todos, es algo obvio a estas alturas. Pero la expresión "igualdad de oportunidades" no tiene siempre el mismo significado. ¿En qué se traduce la igualdad de oportunidades cuando partimos de una realidad llena de diferencias? ¿A qué diferencias nos referimos? Somos felizmente diferentes en cuanto que somos individuos con experiencias distintas en la vida. Además, nos marca fundamentalmente nuestro nivel económico y también la pertenencia a lo que venimos llamando "cultura" y que identificamos con: diferente religión, distinta tradición en la vestimenta y gastronomía, fiestas,etc. Todas estas "peculiaridades" van siendo asumidas por la escuela, lenta pero imparablemente, gracias al trabajo de los docentes.

Sin embargo, más que la vestimenta, más que la alimentación o la religión... el elemento cultural que define de forma más intensa a una persona es su lengua materna. $Y$ en Melilla, el alumnado queda claramente dividido en dos grupos si nos atenemos a este criterio: el grupo de alumnos y alumnas cuya lengua y cultura de origen ( $\left(\mathrm{Cl}_{1}\right)$ (1) es la lengua tamazight (2), y aquellos cuya lengua y cultura de origen (LC1) es el castellano.

Si todas las demás diferencias deben integrar el currículum (y de hecho lo hacen cada vez más)... ¿̇qué pasa con algo tan importante como la lengua materna?

Muy brevemente, la situación de Melilla en cuanto al prestigio sociocultural de las dos lenguas no puede definirse de "bilingüe" sino de "diglósica" (Sánchez y Mesa, 1996), es decir, la lengua castellana sería la "lengua fuerte", la oficial, la que se usa en los medios de comunicación, en los ámbitos académicos, en la administración... mientras que la lengua tamazight es la "lengua débil", no es oficial, su codificación escrita se restringe al ámbito intelectual del estudio de la lengua (Seminario de Lengua y Cultura Tamazight) y a alguna escasa iniciativa impresa en la prensa local (alguna sección en el diario "Melilla Hoy"], al margen de esto su uso se circunscribe al ámbito de las relaciones familiares, al entorno doméstico y de forma oral.

1. LC1: Lengua y Cultura materna. adquirida en primer lugar.

2. La forma más correcta en español, según M. Tilmantine (1998: 25) serla "amazige". pero utilizarè la transcripción "tamazight" que es la que por el profesor Yafar Hassan Yahía en el Seminario de Lengua y Cultura Tamazight de Melilla. 
¿Cómo aborda el sistema educativo esta "diversidad" de lenguas de sus alumnos? (Aproximadamente el 59\% del alumnado de enseñanza obligatoria (primaria y E.S.O) es de LC1 tamazight).

Nos ubicaremos mucho mejor llevando la situación al extremo que lo hace esta viñeta:

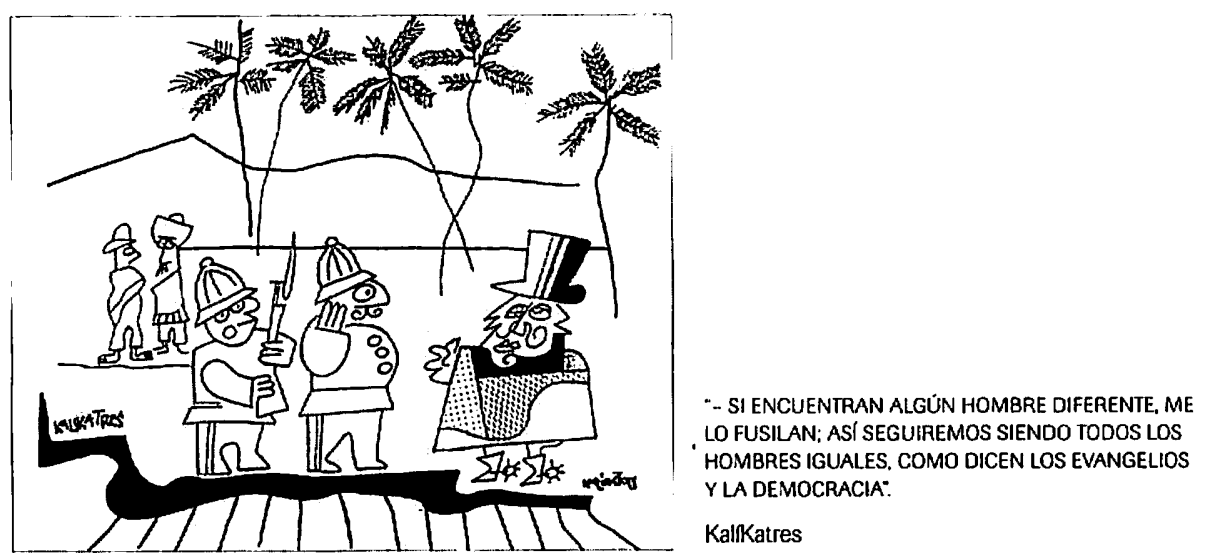

Ante las diferencias lingüístico-culturales, hay dos posicionamientos básicos. En ambos subyace la idea de la igualdad de oportunidades pero conducen a posturas contrapuestas:

A. Eliminando las diferencias (idea llevada al extremo en esta viñeta) tendremos todos las mismas oportunidades ya que partiremos de iguales condiciones. Sería fantástico si habláramos de diferencias económicas pero aquí nos referíamos a las lingüísticas y /o culturales.

B. Gestionando de forma igualitaria esas diferencias, es decir, partiendo de la base de que las diferencias no crean las dificultades, no crean los conflictos, sino que es la desigualdad la que genera esos conflictos. Lo contrario de "igual" no es "diferente" sino "desigual". Es el desigual tratamiento de las diferencias lo que genera crisis.

La postura $A$, enmascarada en premisas "bienintencionadas" nos conduce a una situación de ASIMILACIONISMO, es decir, la cultura dominante absorbe o hace desaparecer o relega a la mínima expresión a la o las culturas más débiles.

Según la clasificación de Arnau J. y otros, citada por Sánchez y Mesa, 1996, combinando las variables "lengua y cultura, medio de educación y objetivos sociales y lingüísticos", los programas educativos se clasifican en: programas de segregación, programas de submersión, bilingüísmo de transición, programas de mantenimiento de la propia lengua y cultura y programas de inmersión.

Pues bien, atendiendo a esta clasificación la situación educativa en Melilla quedaría definida como de: programas de submersión. Los programas de submersión son aquellos "programas regulares en la LC2 (que es la lengua dominante) que no hacen concesiones a la cultura o a la lengua del niño de lengua minoritaria. Su objetivo social y lingüístico es la asimilación". 
Habría que matizar que sí se evidencia cada vez más una clara sensibilidad por incluir elementos de la cultura tamazight en los currícula sin que se llegue nunca a abordar clara y abiertamente los planteamientos lingüísticos.

Los programas definidos como de submersión son programas de bajo grado de éxito, la mayoría de los escolares no progresan a través de este sistema, desarrollan una competencia limitada en la LC2 (3) y.no profundizan en sus propios valores culturales. Una de las características de estos programas es que los alumnos han de aprender los contenidos académicos a la vez que la lengua de instrucción.

Son simplemente programas no pensados para situaciones de diversidad lingüística, son programas para alumnado culturalmente homogéneo (si es que eso existió alguna vez). La táctica de mirar para otro lado seguida por la administración políticoeducativa no sirve sino para acrecentar las cifras de fracaso escolar. Por no hablar de los estragos que causa la falta de autoestima generados por la aculturación y el conflicto identitario (4): "El efecto de la aculturación se vuelve doblemente trágico pues el abandono de lo propio no es garantía de ser aceptado por los otros" ( $M^{a}$ Jesús Vitón. Biblioteca Virtual. OEI). En definitiva, cuando se habla de las peculiaridades de determinados grupos de personas en base a diferentes criterios (lengua, religión, etc), solemos hacerlo desde la posición dominante, considerando las características del grupo fuerte como la "norma" y las peculiaridades del resto de grupos como "diferencias" de esa norma. Es decir, hay diferencias más valiosas que otras.

Pero, si se quisiera dar respuesta a la situación escolar de Melilla desde el posicionamiento B (gestionar de forma igualitaria las diferencias) se debería hacer esfuerzos por poner en marcha programas educativos realmente bilíngües adaptados a nuestra situación particular basados en investigaciones fomentadas en la propia ciudad. Mientras en otros países e incluso en el resto de España, se está planteando la necesidad de facilitar el aprendizaje de la lengua materna del alumnado para que éste no pierda la conexión con su cultura de origen, refiriéndose normalmente a personas inmigrantes o sus hijos, en Melilla, donde más de la mitad de la población escolar española es de LC1 tamazight, el asunto lingüístico apenas se plantea y cuando se hace es motivo de gran controversia. Pero las carencias van más allá de las relacionadas con la lengua materna: tampoco existen programas de apoyo para el aprendizaje de la lengua española, ni juntos (programas de refuerzo del español-programas bilingües), ni por separado, ni en ningún tipo de fórmula novedosa, simplemente se opta por la peor de las opciones: ignorar la realidad.

3. LC2: Lengua y Cultura adquirida en segundo lugar. En Metilla, para aquellos cuya lengua materna (LC1) es el tamazight, su LC2 es el español ya que, aunque sea el idioma oficial, es la que se adquiere en segundo lugar.

4. "El beréber, una lengua carente de estatus social, que no se beneficia del privilegio tradicional y legitimador de lo escrito, confinada a su utitización intra muros 0 . en el mejor de los casos, en la calle, transmitirá, por tanto, a los ojos de los niños berberófonos una imagen desvalorizada de su cultura de origen. De este modo, aquello que deberfa haber constituido los cimientos del edificio identitario del nif̂o se transformará en una herencia pesada y dificil de asumir. Una herencia que. por proyección, personifican. simbólica y físicamente. sus propios padres. ¿Cómo sorprenderse. pues, de que este niño rechace su propia identidad y desarrolle una suerte de "aversión a si mismo" que se expresará, por ejemplo, en la negativa a identificarse con su cultura y lengua de origen y un considerable déficit de autoestima." Mohand Tilmantine. "La importancia de la Lengua y cultura de origen en la integración de las comunidades beréberes en Europa." Taller de Estudios Intemacionales Mediterráneos. "Lengua y Cultura de Origen: Niños marroquies en la escuela española: Ediciones del oriente y del meditemáneo. Madrid. 1999. 
Los docentes debemos satisfacer nuestras necesidades formativas a este respecto a través de vías no oficiales como por ejemplo el "Seminario de Lengua y Cultura Tamazight" cuya titulación no está homologada por el Ministerio de Educación, Cultura y Deportes y en los escasos cursos que se organizan desde los sindicatos sobre lengua tamazight. El Centro de Profesores y Recursos, siguiendo la tónica del ministerio, no ha organizado jamás un curso de esta lengua para el profesorado de Melilla.

\section{Educación de personas adultas: Nivel I (alfabetización)}

En cuanto al ámbito en el que se desarrolla este trabajo, la educación de personas adultas, la situación es similar. El llamado Nivel I o alfabetización, refleja como ningún otro la paradoja.

No voy a detenerme en el concepto de "alfabetización" pero creo que no son necesarias demasiadas disquisiciones para concluir que la alfabetización es un concepto intrínsecamente unido a la lengua materna de la persona que pretende alfabetizarse.

\section{Aprendizaje adulto}

Tradicionalmente se pensaba, e incluso algunos estudios científicos pretendían demostrarlo, que la capacidad intelectual de las personas mermaba con la edad y que por lo tanto las edades más apropiadas para el aprendizaje eran la infancia y juventud. Sin embargo nuevas líneas de investigación concluyeron que la inteligencia de las personas adultas no debía calibrarse con test de tipo transversal donde se comparan mediciones realizadas en un mismo momento a personas diferentes, sino a través de test longitudinales donde se comparan mediciones de la misma persona a lo largo de su evolución y realizadas en distintos momentos de su vida. Estos test longitudinales demuestran la posibilidad de mantener e incluso aumentar la inteligencia hasta la ancianidad. Por lo tanto queda rebatida la idea de que la edad adulta no es adecuada para el aprendizaje, ni siquiera al que aquí nos referimos que es el aprendizaje inicial lectoescritor.

Las investigaciones anteriores habían obviado importantes factores como por ejemplo: el generacional (los jóvenes tienen muchas más posibilidades educativas); los procedimientos de medición utilizan problemas que exigen un conocimiento del medio escolar, un aprendizaje de los rudimentos y rutinas escolares; no se contemplaba la individualización del ritmo, lo que era desfavorable a los adultos; además no se intentaba medir cuáles eran aquellos factores que aumentaban con la edad y los que disminuyen, sino que se valoraba la inteligencia de forma general.

La revisión del mismo concepto de inteligencia, diferenciando la "inteligencia fluida" de la "inteligencia cristalizada" ha sido definitivo para refrendar la capacidad de aprendizaje de la edad adulta.

Según las definiciones de Stevens-Long (1979;102):

"La inteligencia fluida es definida como la innata capacidad cognitiva general reflejada en la realización de test que requieren un pensamiento relacional productivo pero poco conocimiento, experiencia o habilidad de aprendizaje... La memoria instantánea y 
la capacidad de recordar completamente o la respuesta a un estímulo externo pueden ser elementos críticos en la inteligencia fluida".

"La inteligencia cristalizada incluye conocimientos mecánicos y sociales, visualización y razonamiento espacial y certeza en la percepción y racionalización motora... Medidas como el vocabulario, información general, similitudes y juicio, se consideran importantes en las bases de la inteligencia cristalizada...."

Con la edad disminuye la inteligencia fluida y aumenta la cristalizada que está más relacionada con la experiencia y con el contexto en el que se concretan determinadas destrezas. Esas destrezas cobran valor en ese determinado contexto de aplicación y puede que fuera del mismo sean habilidades no valiosas. No se ha considerado valioso, por ejemplo, los procedimientos de resolución de problemas que se han ido adoptando a lo largo de la vida en una situación sociocultural determinada.

El sistema de cálculo y el lenguaje particular para contar, así como el manejo con dos monedas distintas creado por las personas de lengua tamazight de Melilla y su entorno, como veremos más adelante, no se ha tenido en cuenta nunca como un conocimiento valioso. Es un claro ejemplo de una destreza desarrollada en un determinado contexto fruto de la inteligencia cristalizada del adulto. Esto, también debería formar parte del currículum.

\section{Las características generales de las personas adultas que demandan alfabetización en Melilla son las siguientes:}

- Amplia mayoría de mujeres españolas y en menor medida extranjeras en posesión de la Tarjeta de Residencia.

- De confesión musulmana.

- Su lengua materna es la lengua tamazight. (La mujer es la transmisora de la cultura tamazight y probablemente la responsable de su larga supervivencia en condiciones bien adversas).

- Su competencia oral en castellano es muy heterogénea, dependiendo ésta normalmente de su arraigo en la ciudad.

- Padecimiento de un doble aislamiento respecto a la divulgación oral y escrita:

1. Aislamiento oral: Tienen un escaso o nulo acceso a la divulgación de los medios de comunicación de masas orales, ya que en Melilla esta difusión es en la lengua oficial española y en Marruecos la difusión es en la lengua oficial (el árabe dialectal marroqui) con alguna pobre y escasa excepción. Con lo que el aislamiento, a ese respecto, es igual en ambos lados de la frontera. Es decir, toda la comunicación en su LC1 se circunscribe al ámbito doméstico. La dificultad, por lo tanto, para acceder a determinadas informaciones científicas, sanitarias, políticas, culturales, de ocio, etc; son mucho mayores que las que tendria una persona no alfabetizada de LC1 castellana en España o de LC1 árabe marroqui en Marruecos.

2. Aislamiento escrito: En cuanto al código escrito,la inaccesibilidad al mismo es también doble: 
A. Por un lado, son personas que no han estado escolarizadas, por lo que no han aprendido a leer y escribir. Podríamos hablar de un aislamiento de tipo ambiental (pobreza, carencia de infraestructuras de la zona de procedencia, períodos de falta de documentación que los convierte en personas "invisibles", desvalorización de la escolarización femenina, etc).

B. Por otro lado, la lengua que hablan (tamazight) es ágrafa, o mejor dicho, no está normalizada. Son personas que jamás han viso un cartel, un letrero, una indicación escrita en su propia lengua. Podríamos calificar de un aislamiento de tipo político debido a la persecución que sufre la lengua tamazight en todos aquellos países donde se habla o cuando menos, a la falta total de interés de ningún gobierno por intentar protegerla, mantenerla, normalizarla o promover su estudio e investigación.

- Además de la baja autoestima que caracteriza a las personas que inician sus estudios a la edad adulta, se perciben algunos signos de aculturación preocupantes:

- cierta desvalorización de su propia cultura.

- sentimiento de inferioridad de su lengua materna respecto del español y el árabe. Situación que la escuela refuerza desde el momento en que desvaloriza los conocimientos adquiridos en contextos no académicos, no prestigiados socialmente.

- Fuerte rechazo de la fase de oralidad en el aprendizaje del castellano, percibiéndose un proceso de "sacralización de la lengua escrita" (5). Como analiza E. Ferreiro (1997), la lengua escrita ha sido junto con los bienes materiales un instrumento del poder, de las clases dominantes. Las grandes religiones tienen sus libros sagrados. Todo lo que da crédito de nuestra existencia son documentos escritos, todo aquello que nos permite acceder al bienestar debe pasar por una manifestación escrita (escrituras de propiedad, cheques, contratos, títulos académicos, certificaciones de minusvalía, D.N.I, etc). La veracidad y validez que el adulto no alfabetizado concede a la palabra escrita, produce una ansiedad por acceder a ella que les lleva a pensar que todo lo que no es producción escrita no es estudiar, no es digno de perder el tiempo con ello, no es, en definitiva, objeto de conocimiento. (Es un aspecto que redunda en la minusvalorización de su propia lengua y en el posicionamiento acrítico ante lo escrito). La mujer, con un papel fundamental en la transmisión de la cultura de tradición oral, sufre una desvalorización paralela a la desvalorización de lo oral frente a lo escrito. Disminuye su autoestima, por ejemplo, ante los hijos escolarizados. La mujer adulta constata que su saber no es un saber "valioso" ya que el sistema educativo decide qué es "capital cultural" válido y qué no.

\section{Algunos datos sobre la cultura tamazight}

La lengua tamazight es autónoma respecto del árabe, es una lengua camitosemítica (o afroasiática) con similitudes fonéticas y morfológicas a las lenguas semíticas (como el 
hebreo o el árabe) pero muy diferente en aspectos léxicos y en los morfemas utilizados. La cultura tamazight ha sido secularmente oprimida en todos aquellos lugares donde ha estado presente: Marruecos, Argelia, Túnez, Libia, Malí, Níger, Burkhina Faso, etc; siendo amazigh hasta un $50 \%$ de los marroquíes, el $30 \%$ de los argelinos y el $2 \%$ en Túnez. (A esta lista de países podemos añadir España, donde casi el $40 \%$ de los españoles de la Ciudad Autónoma de Melilla son imazighen).

La voluntad política de estos países ha sido la de querer presentar una realidad homogénea cuyas señas de identidad se articulan en torno a la lengua árabe y la religión musulmana. En cuanto a la religión, casi la totalidad de los imazighen son musulmanes sunnitas, pero el proceso de arabización pretendido no ha corrido la misma suerte ya que la lengua tamazight constituye el pilar en el que se sustenta la identidad de esta cultura. Los imazighen poblaban el norte de África antes de la expansión árabe en el siglo VII por la zona, abarcaba el territorio que va desde las Islas Canarias y el Océano Atlántico hasta los límites occidentales de Egipto; y desde el Mediterráneo en el Norte hasta los ríos Senegal y Níger y el macizo de Tibesti al Sur.

Esta extensa zona geográfica está hoy habitada por población de lengua tamazight y árabe (considerada población tamazight arabizada lingüísticamente). Se calcula que el número total de hablantes imazighen son unos 20 millones. Son los pobladores autóctonos prefenicios del norte de África.

\section{Los principales dialectos de la lengua tamazigh son:}

1. el Kabilio en Argelia (taqbaylit). En Argelia la zona de poblamiento lingüístico es muy compacta. Es el habla que ha recibido un mayor impulso modernizador en épocas recientes, en la edición de libros, revistas, reivindicación de uso social... etc. Acaba de ser reconocida como lengua cooficial en Argelia en abril de 2002.

2. en el Sur además del tamazight, el tacelhit (conocido también con el nombre afrancesado de "chelja"). Es el dialecto con más tradición literaria escrita del que se conservan textos en grafía árabe del siglo XVI.

3. el tamaceq hablado por los tuareg en el Sáhara. Es la única lengua que ha conservado hasta hoy la antigua escritura (denominada "tifinagh" y derivada seguramente de la antigua escritura libica).

4. el que más nos interesa es el que se habla en el Norte (el rifeño) tarifit. (2 millones de hablantes en el $\mathrm{N}$. de Marruecos). Es la lengua de las montañas del Rif, de la zona de Melilla y de su entorno; es el área que más emigrantes ha dado a Europa. Concretando más, el habla de la zona de Melilla y Nador (región de Kel'aya, de los iqer'ayen) es el taqer'act. (Tilmantine y otros, 1998).

La civilización tamazight en general es ágrafa. Es una lengua no normalizada y no oficial ni en Marruecos ni en Melilla lo que no impide su uso escrito en algunos periódicos marroquíes como el TWIZA que se publica en francés, árabe y tamazight (con caracteres latinos]. 
En Melilla, la difusión de esta lengua ( $\mathrm{LC} 1$ de casi el 40\% de los melillenses y del $60 \%$ de la población escolar de primaria), se restringe a la existencia del Seminario de Lengua y Cultura Tamazight dependiente de la Ciudad Autónoma de Melilla, dirigido por el único profesor D. Yafar Hassan Yahía, cuya actividad se basa fundamentalmente en la enseñanza del idioma a alumnado casi exclusivamente de lengua materna castellana. Con un raquítico presupuesto y reducida su actividad a la mínima expresión, este Seminario es la única actividad promovida desde la Ciudad Autónoma para satisfacer el punto 2 (h) del artículo quinto del actual Estatuto de Autonomía de Melilla que dice: "Las instituciones de la ciudad de Melilla, dentro del marco de sus competencias, ejercerán sus poderes con los siguientes objetivos básicos:

h) La promoción y estímulo de los valores de comprensión, respeto y aprecio de la pluralidad cultural y lingüística de la población melillense" (6).

\section{¿Alfabetización o aprendizaje de un segundo idioma?}

La alfabetización es un concepto que alude al aprendizaje de las técnicas instrumentales (reduciendo el concepto a su minima expresión) en la lengua materna del alumno, es decir, la lengua que el alumno habla, usa y comprende. Pero no es sólo eso, la alfabetización también alude a la capacidad de decodificar el mundo que nos rodea.

El alumno adulto que habla tamazight como primera lengua se encuentra inmerso en un mundo que necesita "decodificar" y esos códigos que necesita conocer están escritos en castellano. La necesidad del dominio del castellano, por lo tanto, es obvia.

Pero... ¿podemos llamar alfabetización al proceso que se hace con una persona a la que se pretende enseñar una lengua que no habla?

En Melilla hay múltiples programas de alfabetización en castellano cuya totalidad de alumnado tiene como LC1 el tamazigh. Este alumnado ¿se está alfabetizando o está aprendiendo un segundo idioma?

Creo que la respuesta es fácil: si se alfabetizaran lo harian en su propia lengua, en tamazigh. El aprendizaje que están haciendo del castellano es el de un segundo idioma.

Otra pregunta sería pertinente: ¿Hasta qué punto domina el hablante de tamazigh su propia lengua para que le sirva de soporte al aprendizaje de una segunda? (7). La lengua tamazigh es una lengua completa, compleja, dotada del corpus gramatical, semántico, sintáctico y, morfológico de un idioma milenario, pero el abandono a que está sometida y la progresiva "aculturación" que se percibe, puede perjudicarla en el sentido de que sus hablantes empobrezcan su dominio de la misma. Quizá sería necesario un esfuerzo para afianzar este dominio y enriquecerlo, no sólo con la finalidad de que el aprendizaje de una segunda lengua (castellano) se afiance sobre bases sólidas, sino como la plasmación del derecho de un pueblo.

\footnotetext{
6. Artículo $5^{\circ}$. Punto 2. Letra h. ESTATUTO DE AUTONOMIA DE MELILLA. Ley Orgánica 2/1995, de 13 de marzo. B.O.E $n^{\circ} 62$, de 14 de marzo de 1995.

7. "En los años sesenta. diferentes estudios lingüísticos y neurológicos demostraron que el lenguaje de los signos no era pobre, sino al contrario. Pero sobre todo demostraron que no se podia crear en los sordos una competencia lingüistica en una lengua que no conocen. si antes no tienen una natural" Pilar Rodríguez. Directora del Instituto Hispanoamericano de la Palabra. El Pais. 14 de abril 2002.
} 
El artículo 15 de la Declaración de Hamburgo sobre la educación de personas adultas de la $5^{a}$ Conferencia Internacional sobre Educación de Adultos (CONFITEA V) celebrada el 14-18 de julio de 1997, de la Organización de las Naciones Unidas para la Educación, la Ciencia y la Cultura, dice:

15.- "Diversidad e igualdad. La educación de adultos deberá reflejar la riqueza de la diversidad cultural y respetar el saber tradicional y autóctono y los correspondientes sistemas de aprendizaje; se debe respetar y ejercer el derecho de aprender la lengua materna. Una de las tareas más difíciles que ha de cumplir la educación de adultos es la de preservar y documentar la sabiduría oral de los grupos minoritarios, los pueblos indígenas y los pueblos nómadas. A su vez, la educación intercultural debe fomentar el aprendizaje entre y sobre diferentes culturas en apoyo de la paz. los derechos humanos y las libertades fundamentales, la democracia, la justicia, la libertad, la coexistencia y la diversidad".

Emilia Ferreiro (1997) plantea, en relación con pueblos indígenas americanos cuyas lenguas son igualmente de tradición oral, lo siguiente:

"La utilización de la lengua indígena como "puente" para llegar cuanto antes a la lengua oficial ha sido suficientemente criticada y sin embargo, continúa utilizándosela así. Lo ideal es que la lengua indígena sea utilizada a todos los niveles: en tanto lengua de comunicación, lengua de instrucción pero también lengua de reflexión" (8).

Emilia Ferreiro resalta igualmente las dificultades y las largas discusiones respecto a las características de los alfabetos propuestos y este tipo de disquisiciones sobre las que opina que las soluciones gráficas sólo sobrevivirán si la comunidad indígena comienza a utilizar la escritura con diversos propósitos y de forma creciente. "Una proposición ortográfica sólo puede ser concebida como una propuesta y no como una imposición; una propuesta que, además, sólo el uso puede validar" (9).

Por eso "sería necesario pensar en estrategias que impulsen un aumento en el número de productores de textos diversos, así como multiplicar las ocasiones de producción, pensando no sólo en adultos sino también en niños" (10).

Si se sigue hablando de "planes de alfabetización", si todas las instituciones organizan cursos de "alfabetización"... lo que se hace es tratar de alfabetizar a personas tamazighohablantes de la misma forma en que se haría con personas castellanohablantes. No es tan malo hacerlo como no ser conscientes de que se está haciendo. $Y$ esto vale igual cuando el profesorado es de lengua materna castellana o de lengua materna tamazigh.

Klaus Zimmermann refiriéndose al mismo caso en Guatemala: "La educación de los grupos indígenas mayas de Guatemala ha seguido, con algunas excepciones (...), las líneas de la educación destinada a los hispanohablantes. Esto causó una multitud de problemas y conflictos para el niño y la niña mayas monolíngües o bilíngües incipientes: incomunicación, incomprensión, enajenación, miedo, descalificación de la propia 
cultura, desprecio de la identidad, resistencia psicológica, odio a la educación escolar hasta el punto de desertar, y otras consecuencias más" [11].

Si se debieran plantear centros de investigación para la normalización de la lengua tamazigh, si se debieran alfabetizar las personas de lengua materna tamazigh en su propio idioma, si se debieran llevar a cabo programas verdaderamente bilíngües, producir material escrito en tamazight y cómo articular todo eso... son decisiones que, aunque me parezcan idóneas, corresponde a otras instancias abordarlas; pero lo que sí es fundamental es que los docentes seamos capaces de algo tan aparentemente sencillo como describir exactamente el trabajo que pretendemos hacer despojándonos de prejuicios. A estas alturas, quizá más de uno se esté preguntando si es rentable tanto esfuerzo cuando lo que más conviene a los imazighen melillenses es aprender muy bien el español y sólo el español, ya que eso le deparará mejor trabajo y mejor nivel económico y que cuanto menos utilice su lengua materna menos obstáculos tendrá para aprender la nueva. A los que argumenten esto les diría que se hicieran la siguiente pregunta: ¿Queremos una diversidad enriquecedora en nuestra escuela y en nuestra sociedad, que reconozca el valor de la lengua y cultura de casi la mitad de los melillenses o queremos un proceso de asimilación y aculturación?

Si queremos lo primero... cestamos seguros de no estar trabajando para lo segundo?

\section{¿Qué queremos decir cuando decimos "alfabetizar"?}

"Enseñanza de la lengua castellana como lengua de segunda adquisición a personas ágrafas mayores de 18 años de nacionalidad española o marroquíes residentes en Melilla, cuya lengua materna es tamazigh (lengua de tradición oral) y cuya competencia oral en castellano es muy variada: desde un desconocimiento absoluto del idioma hasta un claro dominio de la oralidad, pasando por todas sus situaciones intermedias".

Por lo tanto, mientras la situación no cambie respecto a la lengua materna de nuestros alumnos, el trabajo a realizar cuando decimos "alfabetización" es el anteriormente descrito.

Por otro lado, algunos aspectos positivos a destacar son los siguientes: 1. Van a aprender español en un entorno en el que toda la información escrita y audiovisual es en español y donde podrán practicar con hispanohablantes.

2. El aprendizaje del idioma es un gran estímulo puesto que su aplicación a la resolución de asuntos cotidianos es inmediata. 
3. El aprendizaje del español va a abrir a estas mujeres su campo de relación social, circunscrito al ámbito doméstico y familiar donde pueden desenvolverse en su lengua materna. El hecho de acudir al Centro las hace pasar del ámbito privado al público. ocupar espacio público, visibilidad.

Este trabajo consta de tres partes que incluyen reflexión teórica, trabajo de campo acerca de la lengua y experiencias en el aula:

A. Las reflexiones acerca de la enseñanza del español a personas de lengua tamazight (que ya han quedado expuestas).

B. Indagación acerca de algunos conocimientos previos que una persona de lengua materna tamazight de Melilla y su entorno tiene acerca de: préstamos del castellano en la lengua tamazight y palabras de origen latino, el lenguaje escrito,las monedas y los números. Es decir, buscar en "la información adunada en la memoria" de la que habla J. A. Marina o de la "experiencia colectiva" condensada en el lenguaje recibido de la que hablan Siguán y Mackey. Son conocimientos no validados por la escuela, obtenidos en contextos no académicos.

C. Algunas sugerencias llevadas a la práctica en el aula sobre cómo abordar un proceso e alfabetización de las características ya descritas.

\section{Fundamentos: conocimientos previos, aprendizaje significativo, contextos significativos}

Cuando una persona adulta, de las características que se han expuesto,acude a un centro educativo en demanda de "alfabetización", no acaba de nacer, sino que lleva detrás una mochila bien cargada de experiencias, historias, múltiples recursos utilizados para desenvolverse en el contexto que le ha tocado vivir.

Ya vimos igualmente lo importante que es el concepto de "inteligencia cristalizada" y su relación fundamental con esa experiencia así como la adquisición de determinadas habilidades dentro de unos contextos determinados. Por lo tanto, si con los niños la máxima de Ausubel que hace referencia a los conocimientos previos es de vital importancia,hablando de personas adultas es obligatorio tenerla en cuenta y basar en ella todo el desarrollo de cualquier acción educativa:

"Si tuviese que reducir toda la psicología educativa a un solo principio, enunciaría éste: el factor más importante que influye en el aprendizaje es lo que el alumno ya sabe. Averígüese esto y, enséñese en consecuencia". (Ausubel "Psicología educativa").

El segundo de los objetivos de este trabajo, anunciados anteriormente, es profundizar en los conocimientos previos de los alumnos, teniendo en cuenta que tener una idea clara acerca de los mismos es una de las condiciones para que se produzca aprendizaje significativo (término acuñado por Ausubel en 1963).

El aprendizaje significativo es aquél que puede vincularse a la red de conocimientos previos de la persona. Cuando el aprendizaje es así, significativo, entonces la memorización no es mecánica sino que posibilita la utilización de un conocimiento en la reso- 
lución de problemas prácticos, entre otras cosas, seguir aprendiendo. Pero si la persona que acude al centro educativo tiene una lengua materna distinta de la lengua de instrucción, sea adulta o sea un niño ¿cómo se va a movilizar su experiencia anterior? Serían sólo palabras escolares que apelan a una experiencia escolar. Ni remueven las experiencias previas, ni producen connotaciones cognitivas ni afectivas. El mundo de las palabras y significados escolares queda así cortado del mundo de las experiencias anteriores y externas a la escuela. (M. SIGUÁN y W. F MACKEY. 1986).

El tercer concepto, también relacionado con la idea ya expuesta de la inteligencia cristalizada que caracteriza al adulto, tiene relación con el contexto. Los conocimientos que posee la persona adulta han sido adquiridos en un contexto significativo para él, los conocimientos que queremos que adquiera deben estar igualmente contextualizados y ser significativos, es decir, que enlacen con la red de conocimientos que ya tiene. "El acceso al código debe hacerse siempre dentro de contextos significativos" [lsabel Solé 1994).

Por eso cuando queremos indagar acerca de lo que una persona ya sabe tenemos que tener en cuenta la idea Piagetiana de que los conocimientos se construyen en interacción con los objetos circundantes.

Esas interacciones con los objetos circundantes son las que me interesan en estos momentos.

Aunque está claro que cada persona tiene una experiencia particular e individual y por lo tanto tiene unos conocimientos absolutamente personales acerca de las cosas y para ello sería necesario realizar una buena V.I.A (Valoración Inicial del Alumno), sí existe una serie de conocimientos previos de los que son partícipes una comunidad de hablantes que vive en el mismo contexto.

Ya en el segundo año de vida de un niño, las funciones que desempeñaba el lenguaje gestual pasan a ser ejercidas por el lenguaje verbal. Aparece el signo, un cierto desarrollo intelectual y nuevas funciones del lenguaje. Este ya no es sólo un medio de comunicación, es también medio de organización y de descripción de la realidad, es un instrumento del pensamiento. M. Siguán y W. F. Mackey (1986).

"Usar palabras implica conocer cosas y acciones y combinar palabras implica establecer o descubrir relaciones entre las cosas, organizar la propia experiencia en una representación coherente. Así la adquisición del lenguaje por el niño equivale a una progresiva conquista cognitiva de la realidad, en parte porque por medio de la lengua organiza su propia realidad, en parte porque por medio del lenguaje organiza su propia experiencia y en parte porque el lenguaje recibido de los demás condensa una experiencia colectiva. 0 sea que el lenguaje con el que el niño llega a la escuela y la manera como lo usa resume su visión de la realidad y su actitud ante ella". (M. Siguán y W. F. Mackey.1986).

Si esto ya es así en un niño de dos años ċqué no significará la lengua materna para una persona adulta?

Evidentemente indagar acerca de las construcciones que un adulto ha realizado a lo largo de toda su vida es una tarea titánica que rebasa con creces este mero ecercamiento. Las interacciones a las que aquí me refiero y las que he abordado de momento, son: 
a. qué conocimientos previos tiene el adulto del que hablamos acerca del castellano. aunque no conozca nada del idioma: préstamos del castellano al tamazight, palabras tamazight de raíz latina.

b. qué relación tiene con el lenguaje escrito, qué conocimientos tiene acerca de ese lenguaje escrito (hay, dentro de este aspecto, otros mil que pueden estudiarse), en concreto me he detenido en aquellos mensajes escritos que están en su entorno y que van dirigidos específicamente a ellos, por razones que explicaré más adelante: letreros de comercios.

c. En Melilla, se vive en una frontera entre dos mundos o más, es una frontera que no tiene por qué coincidir con las fronteras físicas entre dos países. Es un concepto más amplio, es una frontera que está dentro de nosotros y nos enriquece. Es una frontera entre varios mundos: el español, el tamazight, el árabe clásico, el árabe dialectal marroquí, el francés (el inglés que todo lo inunda) lingüísticamente hablando; el español y el marroquí (en el aspecto político); el mundo subdesarrollado y el desarrollado (en el aspecto económico); la religión musulmana, cristiana, el laicismo...; el campo y la ciudad; los zocos, mercadillos, supermercados; el dirham, la peseta, el euro; el mundo de transmisión oral tradicional y los medios de comunicación audiovisuales de masas; el mundo oral y el escrito, etc. Es una situación que genera un universo propio que vamos a tratar de explorar, un mundo lingüístico particular para la supervivencia, la comunicación, para decodificar lo que nos rodea.

Entre otros muchos aspectos que pueden abordarse en un futuro, el que estudia el manejo mezclado de las monedas marroquí y española y el lenguaje propio que se crea para ello, así como la tradicional manera de contar en tamazight introduciendo conceptos lingüísticos castellanos así como el cálculo mental, me parece de lo más interesante.

Hay que añadir que el aprendizaje por parte del profesorado cuya $L C 1$ no es tamazight (aunque sea a un nivel muy precario) de la lengua materna de los alumnos genera sobre todo una corriente afectiva que implica el reconocimiento y valoración de su cultura. Además se produce un intercambio de "roles", el profesor pasa a desempeñar el papel de alumno ya que "pronuncia mal" y aprende día a día de sus alumnos que le enseñan su lengua. Esto mejora la autoestima del grupo, favorece la valoración de su cultura de origen y rompe barreras afectivas, culturales y de comprensión.

\section{Conocimientos previos acerca del castellano}

Un hablante de tamazight en Melilla que no conozca nada de la lengua castellana tiene un bagaje nada desdeñable de palabras que usa y que son préstamos del español. Éste es uno de los mecanismos que utiliza el tamazight para crear neologismos. Es decir, esta persona conoce el significado de muchos términos que (con diferente pronunciación) se dicen igual en su lengua materna que en castellano.

Puede ser éste el origen de algunas confusiones debidas a que el profesor cree que el alumno pronuncia mal el castellano cuando en realidad lo que el adulto está haciendo 
es utilizar la palabra castellana como préstamo del tamazight. Es como si le dijéramos a un hispanohablante que cuando dice "restaurante" es que está pronunciando mal el término francés "restaurant".

Cualquier atento oyente del habla tamazight melillense se dará cuenta de la gran cantidad que tiene de préstamos castellanos, también los tienen del árabe y del francés.

Lo que pudiera percibirse como un signo de deterioro del idioma lo aprovechamos como un recurso educativo.

Elaboramos una lista de todos aquellos vocablos que se utilizan en el tamazight y que son préstamos del español. Utilizando la obra del franciscano Sarrionandía "Gramática de la Lengua rifeña" (Tánger, 1905), los diccionarios del también franciscano Esteban Ibáñez y del diccionario editado por el M.E.C, elaboramos un listado bastante profuso de términos comunes en español y en tamazight.

\section{Algunos préstamos del castellano}

\begin{tabular}{ll} 
Castellano & Tamazight \\
Abusar & Abusar \\
Análisis & Análisis \\
Andamio & Ándamio \\
Autobús & Ettúbbis \\
Azulejo & Súlijo \\
Barreño & Erbaño \\
Banco & Érbanko \\
Bata & Báta \\
Bordar & Ábordar \\
Bola & Zabúlat \\
Cáncer & Cáncer \\
Carro & Kárro \\
Cartero & Cartero \\
Cartilla & Cartilla \\
Cepillo & Sípillo \\
Cine & Síni \\
Circo & Sírco \\
Cócina & Cúsina \\
Cocinero & Kúsiniro \\
Contrato & Cóntrato \\
Copa & Kúppat \\
Coche & Cúche. Ettumubi \\
Colores & Kúluris \\
Compra & Cúmpra \\
Corros & Cúrreo \\
Destornillador & Tornillador \\
Doctor & Dúctur \\
Duro & Duru \\
Paquete & Páquiti \\
Pizarra & Písarra \\
& \\
\hline
\end{tabular}


En cualquier pizarra del mercado, carta de menú o letrero en una pared podemos ver los nombres de los productos transcritos tal y como los pronuncia una persona de habla tamazight:

Algunos ejemplos sacados de letreros reales en Melilla y alrededores

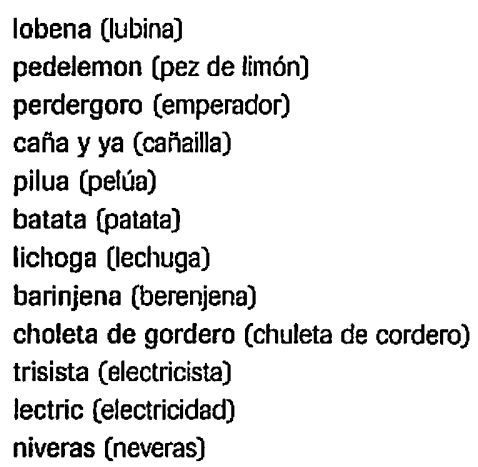

Además existen en tamazight muchas palabras de raíz latina (recordemos el pasado común romano de todo el Mediterráneo). 


\title{
Voces hispano-latinas en la lengua rifeña. Esteban lbáñez
}

Extracto de la recopilación hecha por el Seminario Permanente de Lengua y Cultura Tamazight de Melilla

\author{
arrif: Rif \\ arifi: (arifiy) rifeño \\ arumi: (arumiy) romano, cristiano, europeo \\ asnus: asno \\ eddama: damas (juego) \\ eddoro: (duru) duro \\ erfrank: (frank) franco (moneda) \\ ermakina: (macina) máquina \\ essabon: (ssabun) jabón \\ garro: (garru) cigarro \\ Julinar: (jinjiral) General \\ karrosa: (karru) carro \\ kornita: (kurnita) corneta \\ meryun: (melyun) millón \\ minut: minuto \\ rantina: antena \\ sardin: (assardin) sardina \\ saxxu: saco \\ yuliuc: (Yuliuz) Julio \\ pastiya: pastilla \\ rmario: armario \\ simana: semana \\ sini: cine \\ spitar: hospital \\ ttubis: autobús \\ ttumubin: automóvil \\ qawit: cacahuete \\ marmita: marmita, olla \\ batata: patatas \\ zemanta: manta \\ zeminta: menta
}

Hay analizados más de 130 términos usuales.

¿Existe influencia del tamazight en el español que se habla en Melilla? Seguro que mucho menos, pero alguna hay, al menos algunas expresiones se usan con frecuencia (sería necesario y muy interesante estudiar esta influencia de forma metódica):

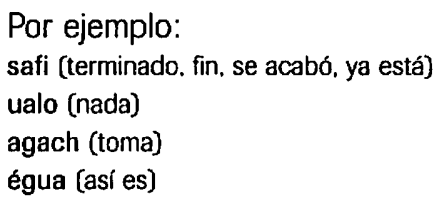

Existiendo todo este universo lingüístico común, es evidente, que tenemos de donde partir. 


\section{¿Qué saben los que creen que no saben?}

En Melilla, por ser una ciudad fronteriza con Marruecos, se utilizan con fluidez los sistemas monetarios español y el marroquí. Es una habilidad que no hay que dejar de conocer y contemplar a la hora de valorar los conocimientos previos de los alumnos en el campo de las matemáticas (y también del lenguaje).
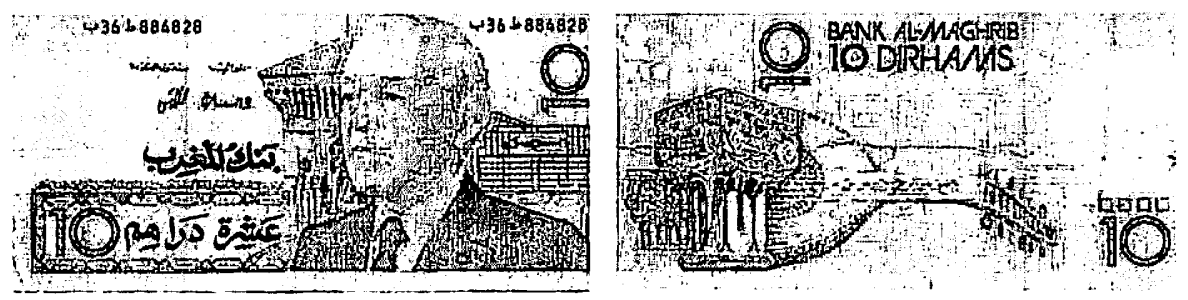

Incluso se ha generado un trasvase o préstamos de palabras castellanas para designar las monedas marroquíes, así, a la moneda de medio dirham marroquí se le dice "duro" y a la de diez céntimos, "peseta". Un dirham son dos "duros" marroquíes; entendiendo perfectamente todo el mundo la diferencia cuando se habla de duros marroquíes o de duros españoles y de pesetas marroquíes y pesetas españolas.

En Marruecos la moneda oficial es el Dirham, 1 dirham son 100 céntimos. Pero el habla popular de la zona de Melilla y sus alrededores no utiliza el término "céntimos" sino "francos". Así en una tienda en Nador te pueden decir perfectamente que un producto cualquiera cuesta 1000 francos, 0 sea, 10 dirham.

Los billetes en Marruecos son de 200, 100, 50, 20 y 10 dirhams. Las monedas son de $10,5,1$ y $1 / 2$ dirham, y las de 20, 10 y 5 céntimos (popularmente francos). La de 10 céntimos es la "peseta" marroquí y la moneda de 1/2 dirham es el "duro marroqui".

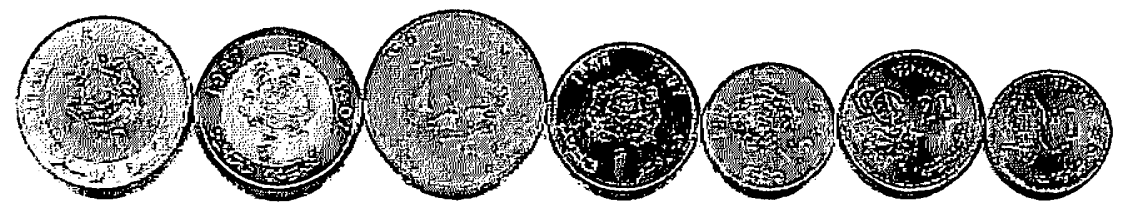

Los números en la lengua tamazight se han perdido todos, excepto el uno (iijen/ij), por lo que los números que se utilizan son los árabes. Hay que tener en cuenta que en español primero se pronuncia la decena y luego la unidad:

Ej. Veintiuno (veinte y uno) 
Sin embargo los números en árabe (que son los que se utilizan también en tamazight) primero pronuncian la unidad y luego la decena:

Ej. wahit u <icrin (21) (wahit: uno, <icrin: veinte)

Ej. mya u wahit $\mathbf{u}<$ crin (121) (mya: cien. wahit: uno, <crin: veinte)

En todas las culturas, sean o no de tradición oral, las personas que no han accedido al código escrito desarrollan una particular manera o maneras de manejarse en el cálculo práctico para desenvolverse en las transacciones comerciales. Esto, que en principio no se percibe como un conocimiento valioso si lo sacamos de su contexto (inteligencia cristalizada), podemos convertirlo en una habilidad que posee el alumno si desentrañamos qué procesos mentales matemáticos utiliza y lo tenemos en cuenta como "conocimientos previos" matemáticos.

Las personas adultas tienen un bagaje de experiencias que son las que han ido conformando su inteligencia y han desarrollado una serie de mecanismos de "supervivencia cultural" muy interesante. No podemos abordar pon tanto la educación en la etapa adulta como si las personas acabaran de aterrizar en el mundo, como si acabaran de nacer. Tenemos que tratar de averiguar cuáles han sido los sistemas que a lo largo de sus vidas les han ayudado a decodificar el mundo que les rodea y que les han permitido desenvolverse con mayor o menor satisfacción en un mundo codificado.

La forma en que dice los números el amazigohablante lleva implíito un cálculo mental: Ej:

\author{
1000: mitayen duru (doscientos duros). \\ 2000: arb<a mya duru (cuatro cien duros). \\ 3000: setta mya duru (seis cien duros). \\ 4000: tmenya mya duru (ocho cien duros). \\ 5000: <cra mya duru (diez cien duros). \\ 6000: ten<acar-mya duru (doce cien duros]. \\ 7000: arbe<tacar-mya duru (catorce cien duros). \\ 8000: settacar mya duru (dieciséis cien duros] \\ 9000: tmenta<ar mya (dieciocho cien duros) \\ 10.000: <crin mya duru (veinte cien duros)
}

Para decir cifras como 7800 sería: "xemmestacarmya u settin duru" (quince cientos y sesenta duros].

La explicación de una alumna de tercero de E.S.P.A (Educación Secundaria de Personas Adultas) es la siguiente:

Mimunt: "Nosotros agrupamos el dinero de 500 en 500 y luego lo que sobra lo decimos aparte". 
En el caso de 7800 está clara la explicación de Mimunt: son quince grupos de 500, 0 sea, quince cien duros y lo que sobra son trescientos, o sea, 60 duros.

Otra alumna, en este caso de primero de secundaria, nos explica un truco:

\begin{abstract}
Malika: "Yo he vivido fuera (en la peninsula) y no sabla comprar en Marruecos, entonces yo qué hacla, me decian, un ejemplo "arbe<tacar-mya", que son 7000 pero yo no lo sabla, para saber yo que eran 7000 ¿qué es lo que hacía?, catorce lo dividia entre dos, entonces me sale que son 7, centiendes? Arba<tacar-mya son catorce billetes de cien duros que son 500 pesetas. Por que si dijéramos 7000, en tamazight es de otra manera" (12).
\end{abstract}

Cuando Malika habla de billetes de cien duros, se refiere al billete de 50 dirham marroquí. Como al medio dirham (moneda muy parecida al antiguo duro español) se le dice "duro", al billete de 50 dirham se le dice "billete de cien duros". Cuando habla de pesetas, se refiere a pesetas marroquies. Quinientas pesetas marroquies son quinientas monedas de 10 céntimos, o sea 5000 céntimos que corresponden a 50 dirham. A la moneda de 20 céntimos se le dice en esta zona "dos pesetas".

Con la introducción del euro, ya observamos cómo la palabra Euros ha sido convertida rápidamente en el término "oros". El valor en pesetas del euro es casi el mismo que el de 10 dirham. Como la introducción del euro es muy reciente habrá que ir observando como el ingenio popular se adapta a los cambios de moneda y sus denominaciones.

De momento, he aquí un ejemplo:

Panadería marroquí, Zoco El Had, cercano a la frontera de Melilla con Farkhana:

Dos barras de pan y dos hogazas cuestan "once doros", ante la perplejidad del cliente europeo, otro cliente marroquí aclara que "son cincuenta y cinco céntimos", o sea, pide por el pan once monedas de cinco céntimos a las que llama "doros" por dos razones:

1. Porque en el anverso de la moneda aparece el " 5 " como en los antiguos duros españoles.

2. Como ya vimos un dirham eran dos "duros" marroquies. Si un dirham vale unas 16 pesetas, "un doro", es decir, medio dirham vale 8 pesetas que es el mismo valor que una moneda de 5 céntimos de euro.

Así sin que la Unión Europea sea consciente de ello, se ha creado el nuevo duro (de euro) que son los cinco céntimos y que vale lo mismo que el "doro"de nuestro entorno marroquí. Tenemos por lo tanto nueva palabra válida para ambos lados de la frontera:

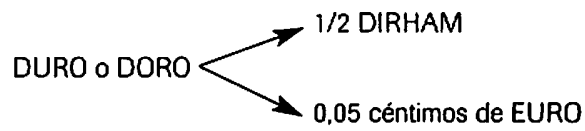




\section{Dibujos que hablan y letras que no dicen nada: la importancia de los iconos para los hablantes de tamazight}

La lengua tamazight, como ya hemos visto, aunque está codificada en algunos círculos intelectuales muy reducidos, no lo está ni oficialmente ni a nivel popular.

Mientras que ningún letrero de la administración en las calles (nombres de vías, direcciones, letreros de información turística o general, advertencias de obras, anuncios de eventos culturales, deportivos o de cualquier otra indole...) ha tratado de llegar a las personas de lengua tamazight, sí lo han hecho los comercios, a los que evidentemente les interesa que la información llegue a sus destinatarios.

$\mathrm{Si}$ analizamos los letreros y carteles de estos comercios a ambos lados de la frontera de Melilla, observamos que la mayoría de ellos (en el lado marroquí prácticamente todos) contienen: elementos icónicos y elementos no icónicos.

A. Elementos icónicos: Un icono es un signo en el que hay una relación de semejanza con lo representado. Los iconos que aparecen en estos letreros y carteles han constituido hasta ahora la única forma escrita de la lengua tamazight o cuanto menos, la única forma gráfica dirigida a informar a las personas de lengua materna tamazight. ¿Qué elementos icónicos aparecen?: los productos que se venden o fabrican en estos establecimientos.

Son dibujos cuya finalidad no es decorativa sino informativa, muy realistas y policromados (por precario que sea el establecimiento). Si el local es tradicional aparecen los iconos pintados en forma de mural sobre la pared y si son más modernos, los iconos no desaparecen, simplemente se modernizan a su vez.

Carnicerias de Melilla. Información icónica influencia de su entorno marroquí. Los letreros más modernos conservan esta información.

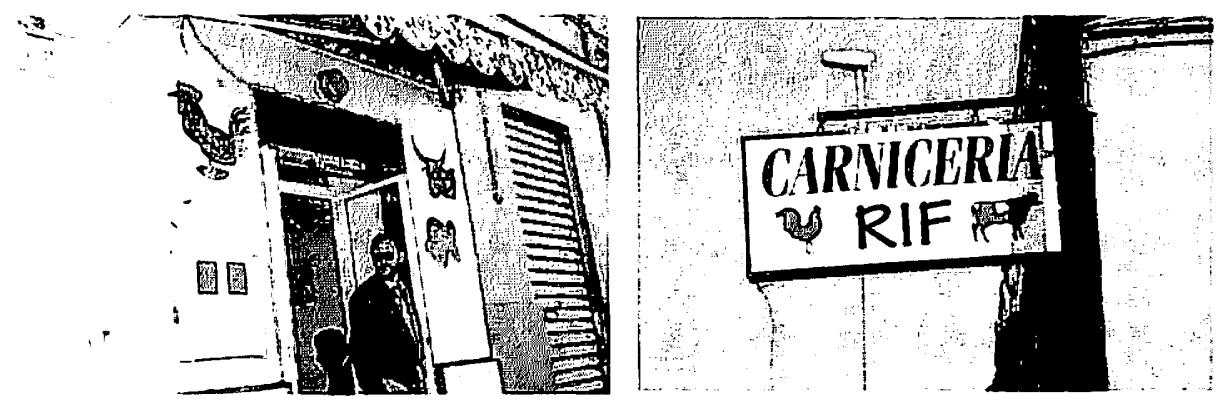


En bastantes ocasiones, esta información icónica aparece distribuida espacialmente como una oración enunciativa en la que se produce una enumeración de productos: Comercio de Nador (Marruecos) a $11 \mathrm{Km}$. de Melilla. Textos: árabe y castellano. Iconos
distribuidos espacialmente como una oración

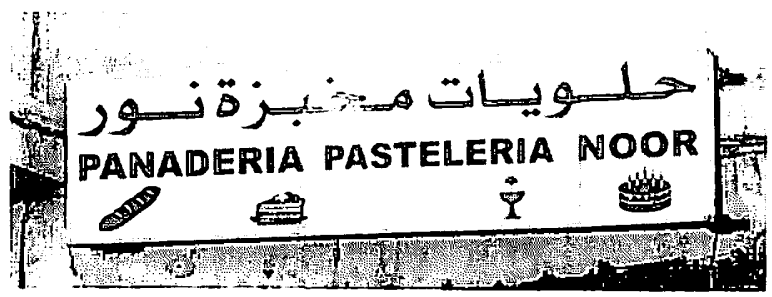

B. Elementos no icónicos: En los letreros de los comercios aparece también una información no icónica. Si estos letreros están en Melilla los encontraremos en español y. bastante menos, en árabe. Si los letreros pertenecen a comercios del entorno marroquí, la información escrita puede aparecer: en árabe, en español y en francés.

Estos letreros también proporcionan información sobre el lenguaje mismo:

1. Aparece la doble direccionalidad de las escrituras árabe (de derecha a izquierda) y castellana y francesa (de izquierda a derecha).

2. Aparecen dos alfabetos diferentes: el árabe y el latino.

3. Son tres idiomas distintos.

4. El hablante de tamazight (tanto el no alfabetizado como el que ha estado escolarizado y domina el árabe o francés) es consciente de que ninguna de esas escrituras es la de su lengua materna.

Comercio en la ciudad de Nador (Marruecos). Los textos aparecen en árabe, español y francés. (Doble direccionalidad, doble alfabeto, tres idiomas. Los elementos icónicos son el único mensaje que entiende el hablante de tamazight que no conoce una segunda lengua.

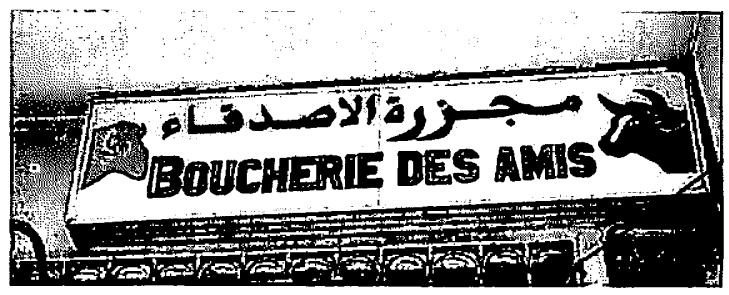


Reflexiones acerca de la enseñanza del español como lengua de segunda adquisición a personas adultas hablantes de tamazight

Comercio de Nador (Marruecos). Los idiomas que aparecen en el texto son el árabe, el francés y el español ("Calsados"), en ambos aparecen elementos icónicos.

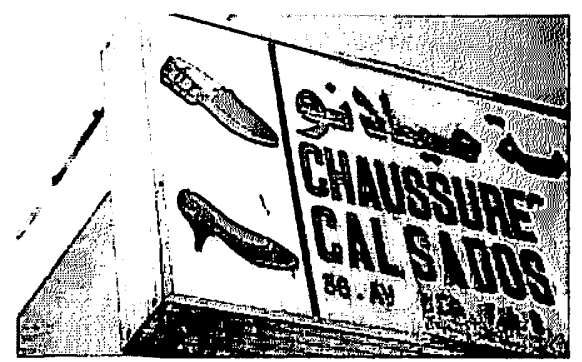

¿Sabriamos decir en qué lugar se encuentra el letrero de la siguiente imagen?. El texto aparece en árabe, español y francés. Los tipos de letra más grande y llamativos corresponden al idioma español. Sin embargo es un comercio de Nador (Marruecos). Un letrero moderno que invariablemente va acompañado de dibujos representativos de lo que allí se ofrece. En Melilla podriamos encontrarlo parecido, sin texto en francés.

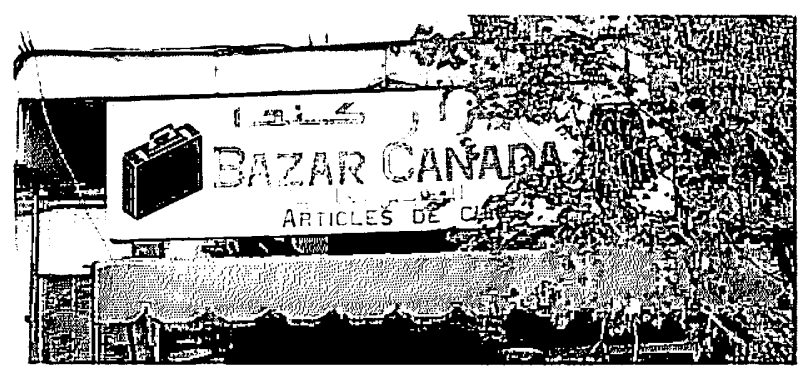

Comercio cercano a la frontera de Farkhana en el lado marroqui. Cualquiera puede saber qué es lo que ofrece aunque no sepa leer el texto en árabe. Los dibujos policromados son de un gran realismo.

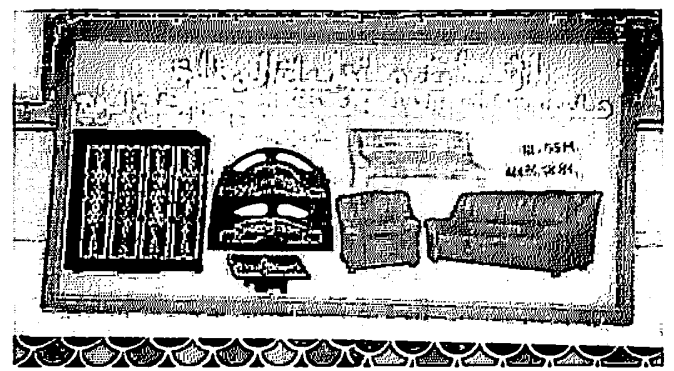


Dibujos de gran preciosismo realizados sobre una pared enlosada. Son los animales de los que se vende carne en esta carnicería de Melilla. Son carnicerías cuyos dueños profesan la religión musulmana y no se venden productos del cerdo.

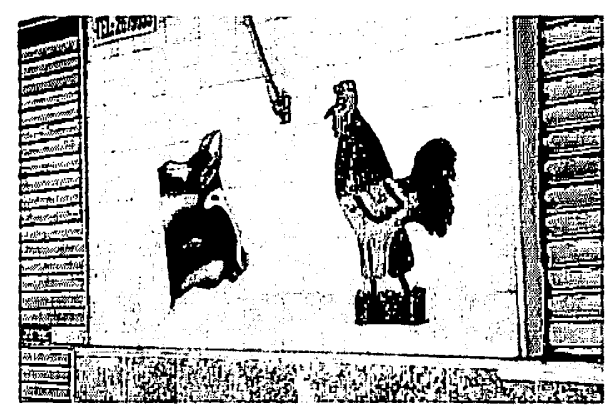

Carnicería de Melilla. Texto en español. Elementos icónicos: animales de los que se vende su carne. Monocromados, debido a su realización no artesanal.

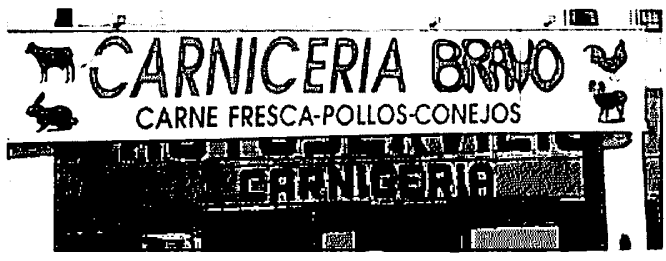

De todas las ilustraciones, ésta es la que más me gusta. El texto no se ve completo pero está escrito en español y árabe. La tienda está entre Farkhana y Zoco El Had (Marruecos). Los dibujos policromados sobre la pared reflejan cómo su dueño ha querido expresar toda la variedad de productos que vende a pesar de ser sólo una carnicería. Un hablante de tamazight que no sepa leer un segundo idioma (árabe o español) está perfectamente informado. Es la finalidad de este despliegue artístico. Un no lector puede "leer" aquí: "se venden pollos vivos, enteros y también en trozos; conejos. carne de cordero y de vaca. leche, pinchitos, salchichas y todo to necesario para hacer un buen cus-cus".

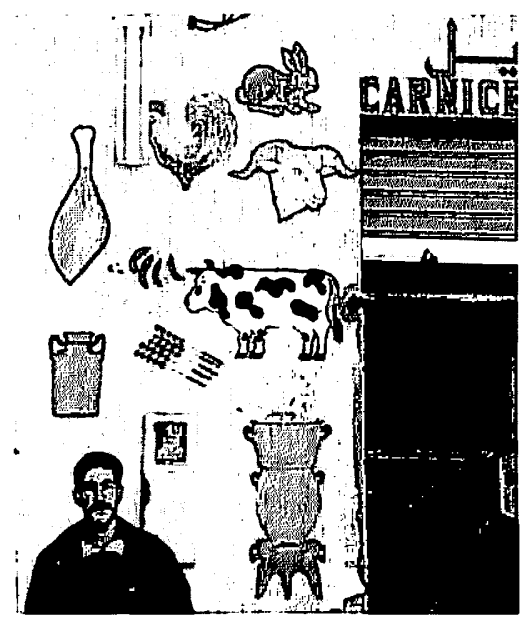


Reflexiones acerca de la enseñanza del español como lengua de segunda adquisición a personas adultas hablantes de tamazight

La peluquería "Melilla" no está en Melilla sino en Marruecos. Además del dibujo de la señora, (con el pelo corto y sin pañuelo), aparecen el cepillo y las tijeras. La flecha que indica la entrada y texto en español y árabe.

La carpinteria Rif, ofrece un muestrario completo de su tipo de trabajo. Están adaptados a un público no lector.

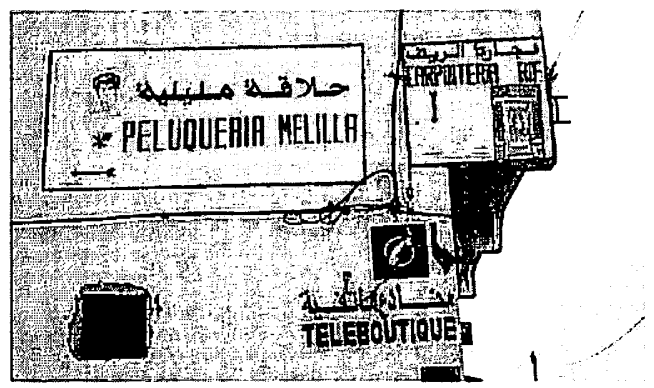

Una mención especial merecen los talleres de coches. Imágenes hiperrealistas, colores metalizados. Textos en español exclusivamente.

El taller se sitúa en una zona rural entre Farkhana y Zoco El Had (Marruecos).

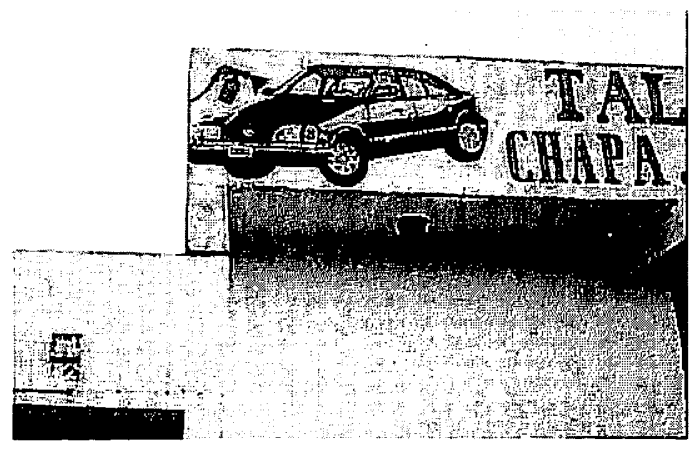

Taller situado en Marruecos, cerca de Melilla. Textos en español exclusivamente. Enorme dibujo policromado

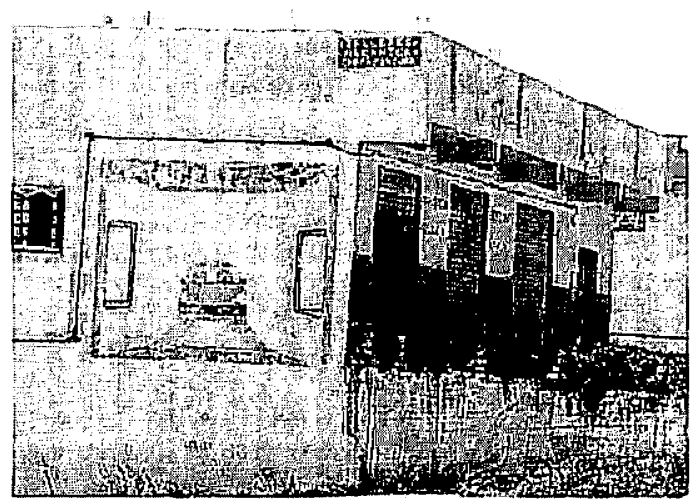


"REPARACIÓN DE RUEDAS". Local de Farkhana (Marruecos), frontera con Melilla. Texto en árabe y español. Doble direccionalidad. Elemento icónico: una rueda. La pared del edificio no está ni pintada pero el dibujo prevalece a la decoración. Es información, es lo que sustituye a la "escritura" tamazight.

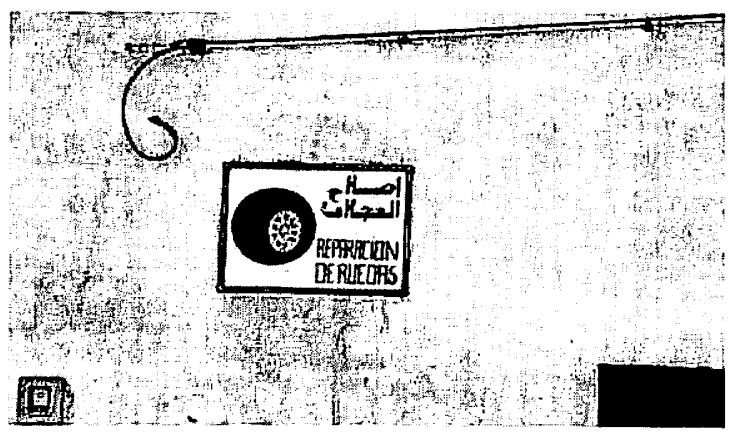

Comercio de Nador. Elementos icónicos: sellos y tampones. Elementos no icónicos: texto en árabe.

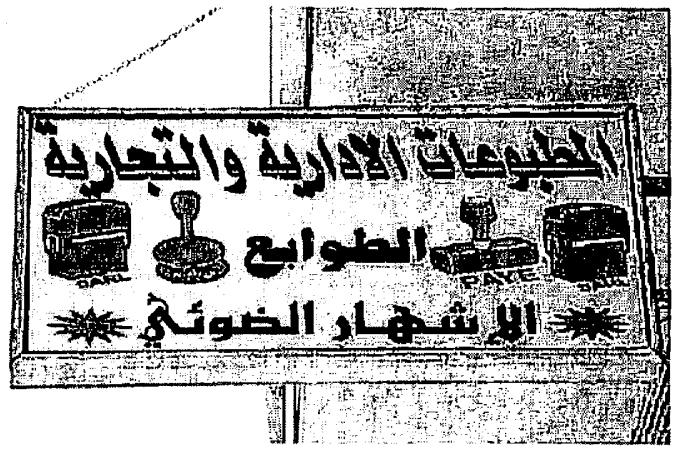

Pollería cercana a Farkhana. Elementos icónicos: pollos, conejos. Elementos no icónicos: texto en castellano y en árabe.

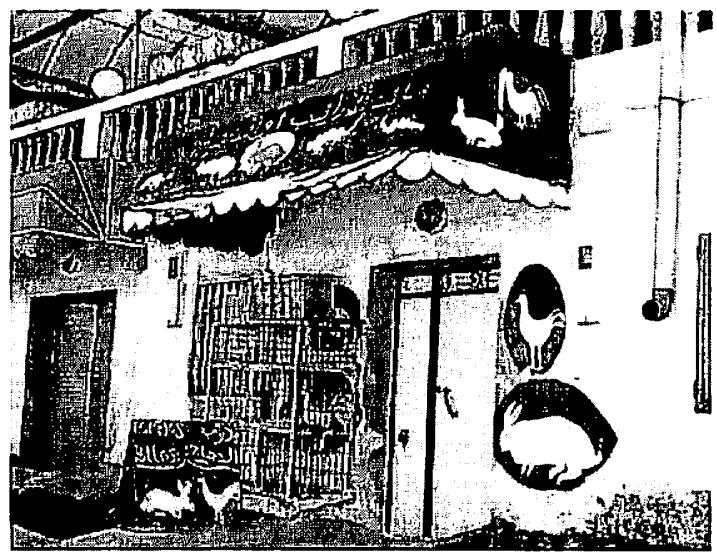


Reflexiones acerca de la enseñanza del español como lengua de segunda adquisición a personas adultas hablantes de tamazight

Letrero de unos baños públicos en la ciudad marroquí de Nador. Elementos icónicos: hombre y mujer duchándose. Elementos no icónicos: texto en árabe y francés.

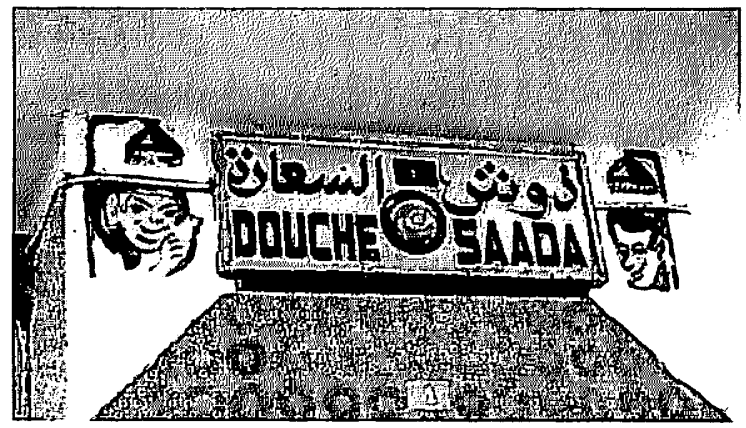

Restaurante de Nador "Marhaba". Textos en francés y árabe. Elementos icónicos: platos de pescado, de pollo, de cus-cus, gambas, pinchitos.

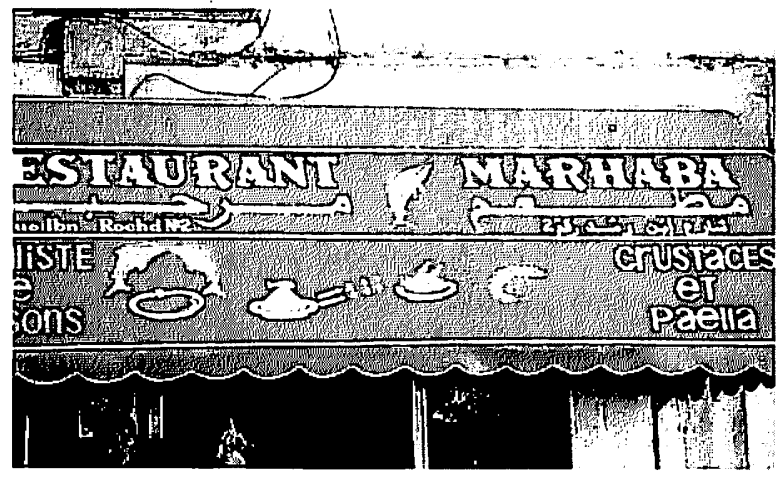

Comercio de Nador. Los textos aparecen en árabe y en castellano. Los dibujos quedan sustituidos por algo que tiene exactamente la misma función: las fotografías de lo que ofrece el comercio.

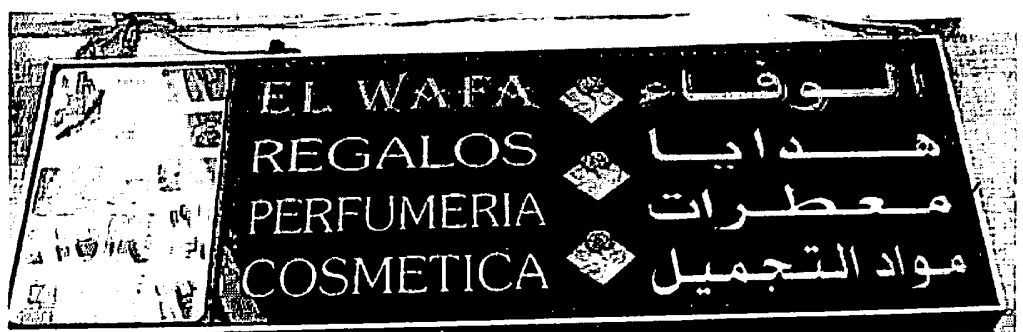


Salón de té y baños públicos en Nador. Los textos aparecen en árabe y francés. En árabe en color azul subrayado de rojo en el lado derecho del letrero (dirección de lectura de derecha a izquierda) y el francés en el lado izquierdo en color rojo subrayado en azul (direccionalidad izquierda-derecha). Los elementos icónicos en el centro: porción de tarta, copa de helado, café. zumos, comidas, gambas. Curiosamente el nombre de las duchas es el de una ciudad española "Marbella".

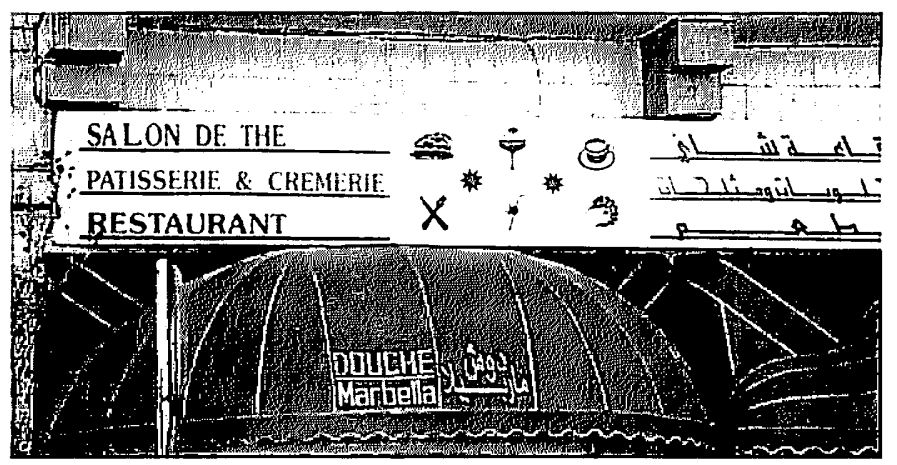

"Sastrería bereber" en Melilla. El dibujo no deja lugar a dudas acerca de la actividad del comercio.

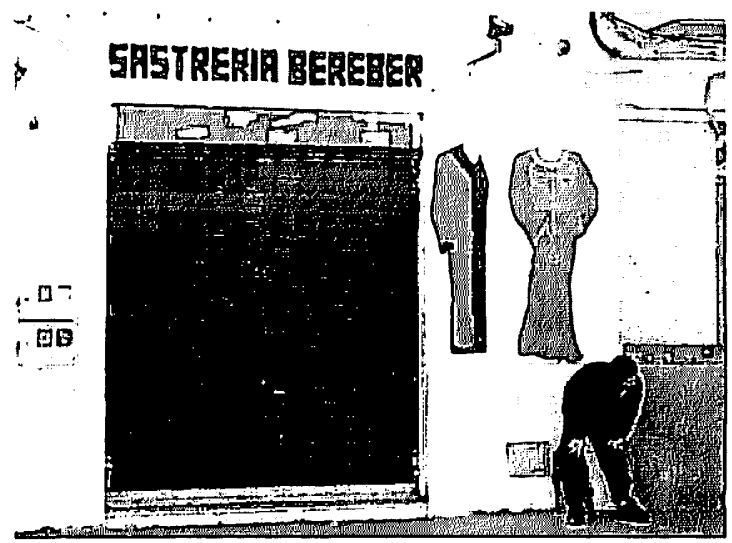


Reflexiones acerca de la enseñanza del español como lengua de segunda adquisición a personas adultas hablantes de tamazight

La "Lechería Número 1" está situada en Marruecos, muy cerca de la frontera de Farkhana. EI nombre del local aparece en árabe (rojo) y castellano [azul]. El dígito"1" se escribe igual en los dos códigos y delimita muy bien el final de cada frase, una escrita de derecha a izquierda y la otra de izquierda a derecha. El resto del texto aparece todo en castellano. PINCHITOS, FILETES, CHULETAS, "HAMBURGUER", HELADOS, POLOS, BATIDOS, "SUMOS", HIELO, LECHE "HAGRIA". Los elementos icónicos vistos de cerca son de un enorme realismo.

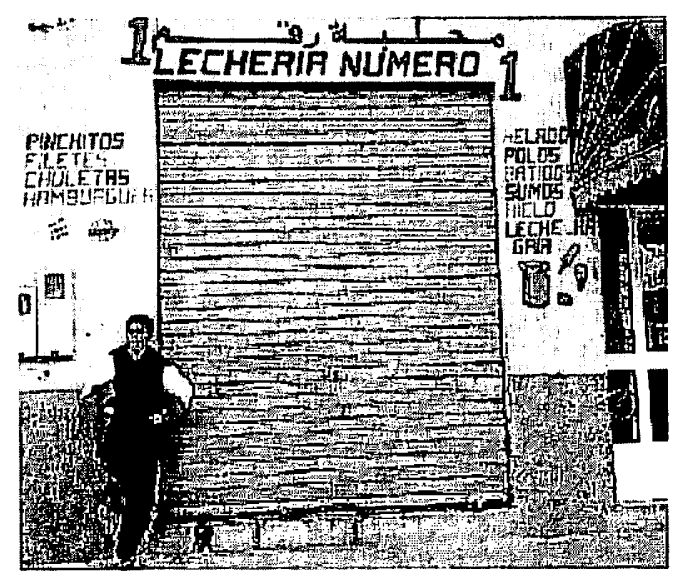

Esta farmacia de Nador tiene sus textos en árabe y francés. Sus elementos icónicos son el símbolo de las farmacias a un lado y la media luna. Lo más interesante es que también aparece la cruz un poco más arriba.

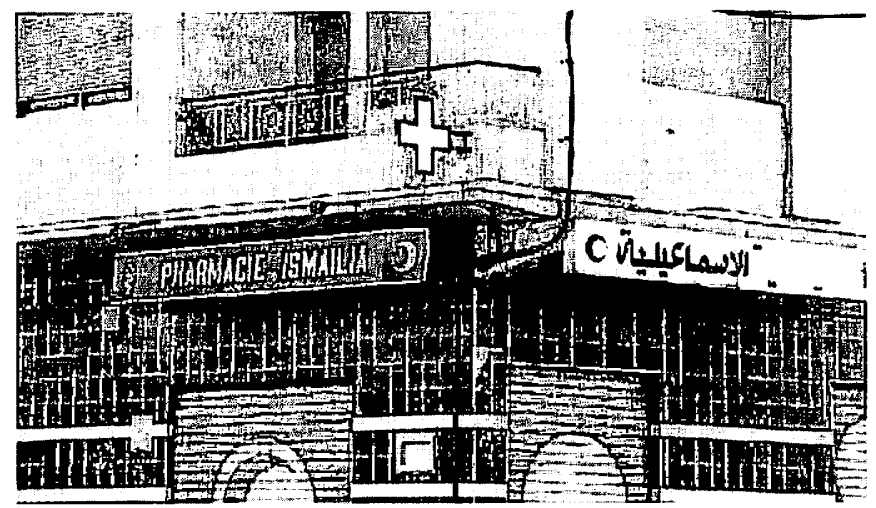


El catálogo de los gimnasios merece también capítulo aparte. Éste se sitúa en Marruecos, en zona rural, en la provincia de Nador, cerca de Farkhana. En todos ellos aparece el dibujo de un culturista en pose. El texto de éste está en árabe y en español dice: "Kárate".

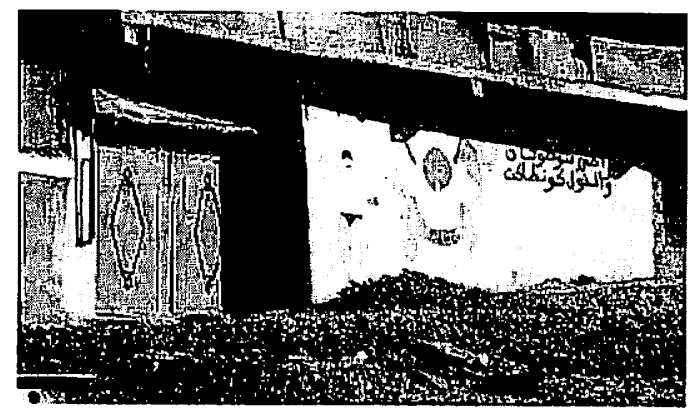

El mismo gimnasio visto desde otro ángulo. El dibujo deja bien a las claras qué tipo de clases se imparten. El texto en este caso es en inglés: "FULL CONTAC".

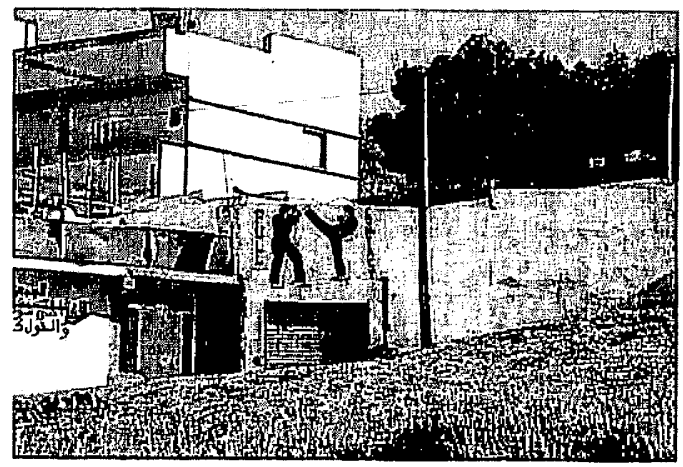

Algunas deducciones podemos hacer a modo de conclusión en este apartado:

- El hablante de tamazight está acostumbrado a ver en la calle textos en árabe, español y francés, por lo que no es de extrañar que no tenga problemas ni confusión con la direccionalidad izquierda-derecha de la escritura española.

- No cabe la menor duda de que el trabajo con imágenes es fundamental, no sólo como apoyo sino para generar significados. El hablante de tamazight se informa en su contexto habitual a través de dibujos muy realistas. Es del todo oportuno que siga siendo así. El dibujo tan realista pretende huir del "dibujo infantil" que menoscaba un poco la autoestima del adulto no lector. Como no podemos disponer de dibujantes tan detallistas lo mejor es recurrir a las fotografías y a los folletos a todo color.

- El adulto no lector tiene una información visual clara acerca de la diferencia entre lo que es una letra y lo que es un dibujo, así como la diferencia del aspecto de las letras árabes y de las letras latinas o "españolas". 


\section{Metodología}

A. Dos grandes lemas presiden este trabajo:

1. "Romper el aislamiento"

2. "Huir del sinsentido"

Para romper el "aislamiento" del que se ha hablado anteriormente y asegurar la comprensión de los contenidos es fundamental organizar charlas, conferencias, tertulias... en lengua tamazight. En Melilla es algo muy fácil de hacer, se dispone de especialistas que pueden hablar en lengua tamazight de cualquier tema. Las charlas pueden ser bilingües (una sola persona habla en los dos idiomas) o una habla en uno y la otra traduce. Un adulto no puede esperar a dominar el castellano para acceder a determinadas informaciones. Es un buen momento para detectar necesidades, deseos de aprendizaje, intereses, etc.

B. Utilización a ser posible de materiales del entorno real. El mundo que nos rodea está lleno de textos: envases de alimentos, productos de limpieza, medicamentos; folletos, menús de comida a domicilio, letreros de la calle, periódicos y revistas, cupones de la O.N.C.E, el billete del autobús, el D.N.I, la T.R, facturas, la cartilla de la Seguridad Social, etc. Se trata de no descontextualizar los textos. Los soportes nos aportan una información acerca de lo que dicen esos textos, nos proporcionan pistas sobre las que podemos hacer predicciones. Descontextualizar es trabajar sin esas pistas.

C. En los materiales creados específicamente para el aula se utilizan sólo imágenes reales, huyendo de los dibujos y la estética infantil que socava la autoestima del adulto. Como hemos visto ampliamente, el alumno de habla materna tamazight está muy habituado a informarse a través de dibujos, pero son dibujos muy realistas que tratan de parecerse lo más posible al modelo. Lo mejor es una fotografía. Fotografías realizadas específicamente para el aula o aprovechar el ingente material impreso y a todo color que se genera a diario en cualquier ciudad (sin olvidar INTERNET).

D. En las imágenes utilizadas se procura que aparezcan personas y elementos de diversas culturas, tanto de Melilla como de otros lugares del mundo.

E. Se asocia la imagen a la palabra en castellano y a veces a la palabra escrita en tamazight. Se trata se que puedan trabajar a la vez personas que tienen diferentes ritmos de aprendizaje, el que aún no lee nombra la foto, aprende vocabulario oral y el que lee puede hacerlo porque tiene la palabra escrita. (Una característica de los grupos de alumnos adultos es su heterogeneidad].

F. Todo lo que se lee y escribe no sólo ha de tener sentido y ser significativo sino que se procura que cumpla alguna de las funciones del lenguaje: comunicación, recupera- 
ción de la memoria, recogida de información, etc. Es decir, se huye del "uso escolar" de la lengua y buscamos el "uso social" de la misma (RocKwell, 1982).

G. Para el hablante de tamazight que no conoce el castellano, éste no produce significados puesto que es una lengua que no domina, sus signos no pueden actuar de "caña de pescar", utilizando el símil de J. A. Marina. Con los significantes en castellano no pueden "pescarse" significados que no se tienen.

"El significado es algo que uno aporta al lenguaje escrito en lugar de extraerlo de él" (Frank Smith, 1990) por eso es interesante, por un lado comenzar con préstamos del castellano al tamazight, con los datos del D.N.I de cada persona que sí son significativos y creando los significados a través de las imágenes y las dramatizaciones, así como la utilización de vocabulario tamazight. Si el profesor es de Lc1 tamazight no tiene problema en este sentido y si no lo es sería interesante que aprendiera un poco de esta lengua o ayudarse de las traducciones de un alumno que tenga más nivel de castellano oral.

H. Se puede comenzar trabajando, como decía anteriormente, con el D.N.I, el texto más significativo para el alumno y con los préstamos del castellano al tamazigh para lograr conectar con los conocimientos previos del alumno.

I. La secuenciación en sílabas directas, trabadas, compuestas, etc, supone un pesado lastre que nos lleva a segmentar el lenguaje, a tratar de simplificarlo en una supuesta gradación de dificultad que trae como consecuencia la creación de un lenguaje específicamente escolar, la creación de unos textos forzados que no podemos leer en ningún otro sitio más que en la escuela, no tiene ninguna de las finalidades del lenguaje y carecen de significado o tienen un significado forzado, irreal, ajeno a las necesidades comunicacionales de los alumnos.

Además ćquién decide qué sillabas son más fáciles y cuáles más difíciles? Para unos alumnos cuyos nombres son Rachida Bnahmane, Asmae Azaryouh. Abderrahman, Fattouma... etc, o sus lugares de nacimiento son: Tlat-Yebal (Beni Sidel), Beni Bouiahie, Farjana, Beni Chicar, Aruit, Ain Aichan Taounat, Kebdana, Setout (Nador) etc; estos nombres son más significativos que palabras aparentemente de composición silábica más "fácil" pero que no les generan ningún significado: ej. "maná" o "mani" y que les crea una gran confusión ya que la fonética les suena muy similar: ej, tela, tele, tila, etc. (Consideremos la frecuente confusión fonética entre las vocales $e-i$ y las vocales $o-u$ ). Como dicen E. Ferreiro y A. Teberosky (1979), cuando se fragmenta el lenguaje escrito, aunque se sumen luego las piezas ya se ha perdido la relación fundamental entre el significado y el significante. 
J. Metodología de trabajo por proyectos o pequeñas tareas: se organiza el curso en torno a varios proyectos en los que el lenguaje se utiliza en situaciones comunicacionales reales. Se trata de utilizar y practicar el lenguaje español en situaciones diversas, en contextos reales y siempre con sentido.

Algunas tareas pueden ser: cumplimentar los datos personales de diferentes impresos, pedir un desayuno en una cafetería, comprar en un comercio los productos de una lista de la compra, mandar una postal a un familiar, etc.

K. Se recuerda mejor el nuevo vocabulario más que por familias semánticas por familias significativas, por ejemplo, "productos de una lista de la compra", "prendas de vestir" etc.

L. Como existe un fuerte rechazo a la práctica del lenguaje oral ya que el alumnado no le da valor académico, es conveniente en vez de dedicar una clase entera a este tipo de actividad hacerlo en tiempos cortos, en rutinas diarias, prácticas de estructuras que se vayan detectando como necesarias al inicio de cada clase y mezcladas con otro tipo de actividades.

LL. Se tienen unas necesidades orales, otras escritas y otras diferentes de lectura y sería muy complicado centrar nuestros esfuerzos en tratar de escribir frases que entrarian dentro de las necesidades orales, como por ejemplo: "ipor favor, a cuánto están las patatas?", mientras que a nivel escrito lo que necesitamos es saber escribir los nombres de los productos y leer los envases de los letreros de los supermercados, por ejemplo.

M. Muchos compañeros expresan ansiedad ante la carencia de un material concreto tipo "fichas" para trabajar. Sin embargo, no es cierto que ésta sea una forma caótica de trabajar, también se utilizan "fichas" en el sentido de que cuando estamos realizando cualquiera de las tareas se necesita escribir una serie de palabras cuyo significado ya conocemos y sabemos por qué y cómo vamos a utilizarlas pero necesitamos la destreza instrumental. Añado, al final, algunas fichas a modo de ejemplo dejando claro que, cualquier ficha de este estilo que se elabore para los alumnos debe formar parte de un proyecto y una tarea previa y debe ser una necesidad de escritura dentro de un contexto de trabajo, es decir, lo que se hace con estas fichas no es escribir, es caligrafía u ortografía, "escribir" es mucho más que copiar palabras y perfeccionar el trazo de letras. 


\section{Sugerencia de actividades y utilización de material en la enseñanza de español como lengua de segunda adquisición a personas adultas hablantes de tamazight}

(Las actividades aqui expuestas han sido llevadas a la práctica por las profesoras Yamila Mohamed Maanan y Mª Ángeles Sánchez Suárez con diferentes grupos de Nivel I de Educación de Personas Adultas).

\section{El D.N.I: un texto completo y lleno de significado}

Si para una persona adulta el carnet de identidad es un documento de gran valia y significado, un texto completo, lleno de información fundamental (nada menos que sobre nosotros mismos); para muchos adultos de Melilla es, con mucha propabilidad, el "papel" más deseado, el documento que abre las puertas, que posibilita la entrada al Estado del Bienestar, que hace a las personas visibles.

No podemos olvidar que muchos de nuestros alumnos poseen Tarjetas de Residencia o Permisos de Trabajo, algunos de ellos son documentos provisionales, con validez por un año.

Incluso muchas de estas personas que hoy son poseedoras de un D.N.I tuvieron que luchar por él en el año 1986 ya que la promulgación de la Ley de Extranjería pretendía convertirlos en extranjeros en su propia tierra. Es un documento que está dotado, por lo tanto, de un valor añadido.

Pero además, el carnet de identidad es un texto ideal inicial porque reúne una serie de virtudes:

- Significación de tipo políticosocial. (No olvidemos nunca a Freire)

- Es un texto acerca del cual el alumno puede predecir lo que pone: el adulto sabe perfectamente que en él podemos encontrar su nombre y apellidos, su dirección y su fecha y lugar de nacimiento.

- El alumno sabe perfectamente que datos como, por ejemplo, el número de teléfono no aparecen en el D.N.I. Esto es fácilmente comprobable en el momento de la matrícula, cuando se le piden datos como el lugar de nacimiento, la fecha o la dirección te acercan el carnet para que lo leas. Si se les pide el teléfono te dan un papelito con el número apuntado. Es decir, el alumno tiene unos conocimientos previos acerca de este texto, aunque no sepa leer lo que pone, sabe perfectamente lo que debe poner.

- Es un texto real, es decir, es un texto en su correspondiente soporte, no privamos al alumno de la información suplementaria y fundamental que éste le aporta. Si lo mismo que pone el D.N.I se lo escribiéramos en un folio, seguro que no sabría absolutamente nada acerca de lo que dice. Sin embargo, el texto en su soporte real nos da muchísimas pistas.

- EI D.N.I tiene una gran funcionalidad, es un texto que hay que consultar muchísimas veces ya que debemos rellenar impresos donde se nos solicitan nuestros datos personales. 
O sea, que es un texto acerca del cual el alumno tiene una información previa y por lo tanto puede adelantar hipótesis de lectura, conecta con sus conocimientos previos ya que, aunque no sepa hablar español sí sabe su nombre, su dirección, dónde ha nacido, etc, y sobre todo, sabe que esos datos están en esa tarjeta escritos.

También ofrece ciertas dificultades que no se aprecian más que con la práctica:

- Transcripciones mal hechas, afrancesadas (Ej: Nounout, léase "Nunut").

- El mismo nombre escrito de formas distintas (Ej. Fadma, Fatma; Yamila, Jamila; Hadiya, Jadiya, Hadilla, Jadilla, etc).

- Fechas de nacimiento en las que sólo figura el año ya que no consta el día ni el mes.

- Fechas de nacimiento que no concuerdan con la edad real de la persona.

- A veces aparece el "patronímico" (nombre de la familia extendida rifeña) y a veces no.

- Sistema de apellidos ajeno a sus tradiciones (donde sólo aparecería un apellido: el del padre].

- Grupos consonánticos extraños al castellano, como por ejemplo: Farkhana (localidad fronteriza con Melilla), Abderrahman (nombre de varón), etc.

- A veces el carnet está sellado de forma que no se ven bien las letras (se puede fotocopiar a mayor escala].

Pero la realidad es que necesitamos manejar estos datos tal y como están escritos en el D.N.I, pudiendo encontrarnos con problemas si no lo hacemos así, ya que no habría concordancia con lo que dice el documento. Así que, en este caso la realidad debe imponerse a la corrección escolar, y si hay dos alumnas que se llaman Fadma y una tiene su nombre escrito con "t" y otra con "d", así tiene que ser. Otra posibilidad es iniciar un proceso para arreglar los datos que no estén correctos, pero es una posibilidad que produce "risa nerviosa".

La utilización del D.N.I es meramente funcional:

- Se pone el nombre al material escolar (carpetas, libretas...) mirando del modelo.

- Se rellenan algunos impresos sencillos conforme vayan haciendo falta a los alumnos, cada uno va a su propio ritmo, ya que para rellenar un impreso aunque sólo sea para poner el nombre se necesita identificar la palabra "NOMBRE".

Para familiarizarse con el documento se pueden hacer múltiples actividades: reconocer el carnet propio entre los de otros compañeros, (previamente focopiados y plastificados), agruparlos cuando los nombres empiezan por la misma letra, alinearlos por el orden en que se está sentado, etc. Son actividades que obligan a detenerse en las letras y comparar los datos. 


\section{El calendario}

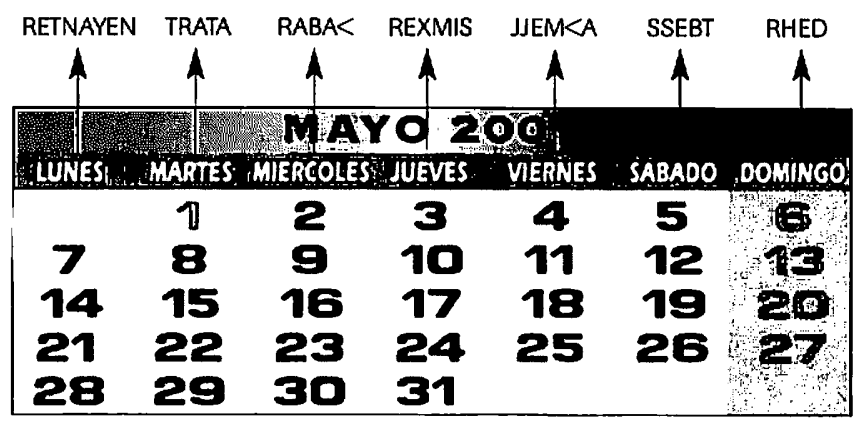

Los números auténticos de la lengua tamazight se han perdido, excepto el uno (iijen/ij) una (ijten/ij).

$\begin{array}{ll}1 \text { wahit } & 17 \text { sbe }<\text { tac } \\ 2 \text { tnayen } & 18 \text { tmentac } \\ 3 \text { trata } & 19 \text { tse }<\text { tac } \\ 4 \text { arb<a } & 20<\text { crin } \\ 5 \text { xemsa } & 21 \text { wahit } u<\text { icrin } \\ 6 \text { setta } & 22 \text { tnayen } u<\text { crin } \\ 7 \text { seb<a } & 23 \text { trata } u<\text { crin } \\ 8 \text { tmenya } & 24 \text { arb }<a \mathrm{u}<\text { crin } \\ 9 \text { tes }<\text { a } & 25 \text { xemsa } u<\text { crin } \\ 10<\text { acra } & 26 \text { setta } u<\text { crin } \\ 11 \text { hid }<\text { ac } & 27 \text { seb }<a ~ u<\text { crin } \\ 12 \text { ten<ac } & 28 \text { tmentac } u<c \text { crin } \\ 13 \text { trettac } & 29 \text { tes }<\text { a } u<\text { crin } \\ 14 \text { arba<tac } & 30 \text { tratin } \\ 15 \text { xemmestac } & 31 \text { wahit } u \text { tratin } \\ 16 \text { settac } & \end{array}$

Para trabajar con el calendario es necesario tener uno muy grande en el aula y también fotocopiar el mes correspondiente para facilitar el manejo.

El adulto debe recurrir con mucha frecuencia a este "texto" y entenderlo le será de gran ayuda: saber cuándo tiene las citas del médico; saber en qué día está mirando el calendario; saber cuántos días faltan para un cumpleaños, una fiesta o cualquier otro acontecimiento más cotidiano... No sólo conocer y saber decir en español los meses del año y los días de la semana, asi como los números de los días del mes, sino también entender el uso del mismo: pọder localizar en el calendario que el 14 de mayo era lunes, etc. También es necesario identificar los números de los meses (así vienen en el D.N.I). 
Pueden mezclarse actividades matemáticas: Cuánto falta para tal día, cuántos días han pasado desde...

Trabajando con pequeños proyectos, el calendario se puede convertir en una rutina diaria: mirar la fecha y escribirla, señalar el día que se va a organizar cualquier actividad, etc

\section{Letras móviles}

Se confeccionan varios juegos de letras que posteriormente se plastifican con la finalidad de utilizarlos como complemento de la escritura. Los alumnos forman sus nombres y el de sus compañeros con el modelo delante (para aquellos que lo necesiten) del carnet de identidad. Se pueden utilizar a lo largo de todo el curso para poner todo tipo de mensajes y en diversas situaciones.

Las letras móviles son especialmente cómodas para aquellas personas más mayores con dificultades de motricidad fina y para un alumno que tiene problemas graves de movilidad en la mano derecha. Ha habido que incrementar en los juegos de abecedarios más letras " $h " y$ " $k$ ", etc, que son más frecuentes en los nombres en tamazight. En la escritura con letras móviles se refuerza la capacidad de observación y se facilita la autocorrección.
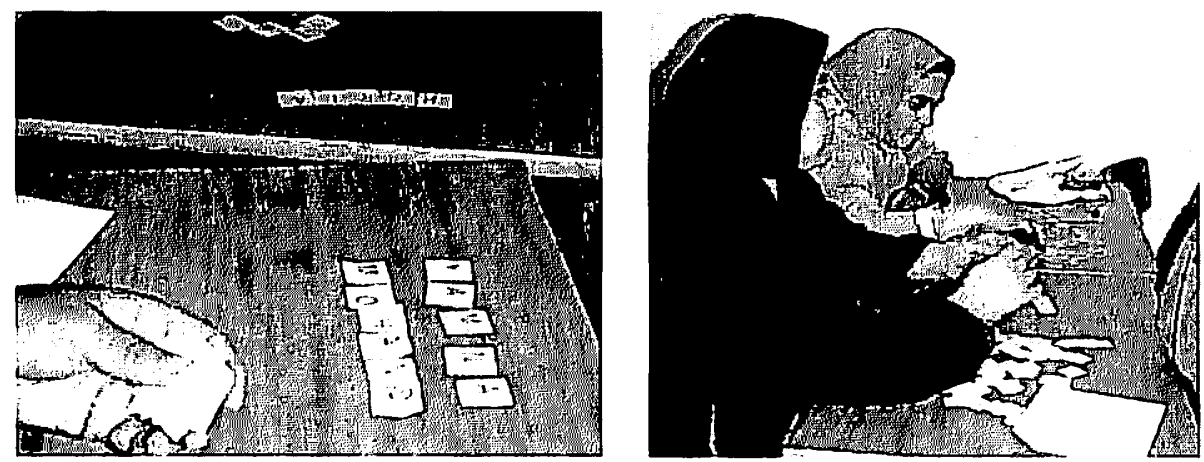

\section{Folletos: papel satinado y a todo color}

Es impresionante la cantidad de papel impreso y a todo color que se genera en nuestra sociedad de consumo. Todas las semanas se inundan nuestros buzones con información de todo tipo. Alguna de esta información, independientemente de consideraciones ecológicas, nos es muy útil. Saber leerla es fundamental: ofertas, diversos servicios, actividades de la ciudad, etc.

Sin necesidad de crear un material específico para leer en la escuela, desde el principio nos hemos propuesto utilizar lo que ya existe en la vida real y con lo que tenemos que enfrentarnos a diario. Utilizamos para ello estos folletos a todo color que llegan a diario a nuestros buzones, a ser posible utilizaremos los de la semana en curso, así de paso nos sirve para nuestra vida real, que es de lo que se trata. 
El grupo tiene muchísima información previa acerca de lo que se nos ofrece en los folletos, también acerca de los precios, saben que hay cosas más caras y otras más baratas, lo saben sólo con ver la foto. Se trabajan los precios, ordenándolos de más caro a más barato o viceversa (cada persona lleva su propio ritmo y se fijan en la longitud de las cifras o en que el primer número es el más alto). Las actividades, tanto del campo de conocimiento de las matemáticas como del lenguaje, son innumerables: agrupar todos los productos que son más baratos que uno dado, hacer listados de productos de alimentación, agrupar los alimentos según un criterio determinado, confeccionar una lista de la compra para la elaboración de una merienda o de un menú cualquiera y calcular luego cuánto dinero vamos a necesitar, etc.

\section{Los cupones: un texto de matemáticas}

En consonancia con los criterios adoptados desde el inicio de este trabajo, los materiales salen de la vida cotidiana, no son materiales escolares.

Los cupones de la O.N.C.E son comprados con mucha frecuencia por los alumnos, que los conocen por sus motes: el león (30), la muerte (00), la mudanza (69), la pipa (61), el piojo (62), la escalera (74), el maestro (71), la agonía (99), etc.

Los cupones reúnen por lo tanto, varios requisitos imprescindibles para su uso como material en el aula: ser un material usado por los adultos en su vida cotidiana, proporcionar situaciones de aprendizaje, resultar un material estimulante, entretenido, manipulable y tener capacidad de adaptarse a los diferentes ritmos de aprendizaje y a la diversidad de situaciones iniciales de las que parten los alumnos adultos.

La O.N.C.E nos proporciona los cupones no premiados, en concreto las cien primeras terminaciones. Las plastificamos y con ellos se hacen multitud de actividades adaptadas al nivel de cada uno y a su ritmo individual.

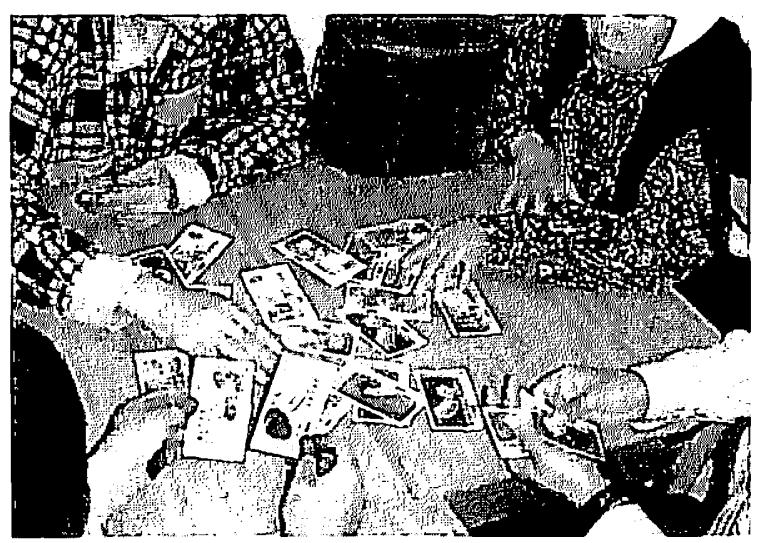


Reflexiones acerca de la enseñanza del español como lengua de segunda adquisición a personas adultas hablantes de tamazight

Aprovechando la rutina diaria del aula, cada día se comprueba en un periódico local cuál ha sido la terminación premiada y se busca en nuestros cupones (discriminación visual) la terminación que ha salido. Se ordenan las terminaciones desde el 0 al 99 , se hacen series de cinco en cinco (hay que recordar la facilidad de contar en base cinco que ya hemos visto con las monedas], de dos en dos, etc.

\section{Los envases: literatura necesaria}

Cuando no se sabe leer, una tarea tan sencilla como hacer la compra puede convertirse en algo angustioso. Ir al mercado y pedir productos frescos es una actividad que entra en el campo de la comunicación oral, además, en Melilla, las personas hablantes de tamazight no tienen ningún problema ya que los vendedores suelen ser también amazigohablantes. Pero, cuando los productos son envasados y se ofrecen en un supermercado donde hay que autoabastecerse, la tienda se convierte en un lugar inhóspito y el acto de comprar en una tarea difícil.

La mejor manera de aprender a leer los envases es con los envases sobre la mesa. Se trata de que no privemos a la persona de toda la información que nos aporta el soporte del producto. Todo el mundo sabe cómo es una botella de agua, de leche, una lata de atún o un paquete de té. Además, estos envases están llenos de fotografías a todo color y el formato de la caja, bolsa o botella nos ayuda a deducir qué es lo que tenemos entre manos.

1. Primero se recopilan los envases más adecuados, aquellos que pensamos que son de consumo más habitual (evidentemente no vamos a utilizar envases de productos muy caros o poco habituales].

2. Como ya sabemos el siguiente paso consiste en "nombrar" el objeto, ya que para los alumnos de habla tamazight la botella de agua está muy claro qué es lo que contiene: "aman" (agua, en tamazight). Es decir, tenemos que lograr que verbalice el significante castellano asociando su significado no a esta palabra (que por sí sola no genera en ellos ningún significado] sino al objeto.

3. Para ello se pueden hacer ejercicios de oralidad como el siguiente:

Sentados alrededor de los envases (como si fuera una tienda) cada persona coge un envase y dice: "Voy a la tienda y compro atún..., la siguiente añade otro producto y nombra el anterior. Así todas las personas escuchan el nombre del producto a la vez que se coge de la mesa.
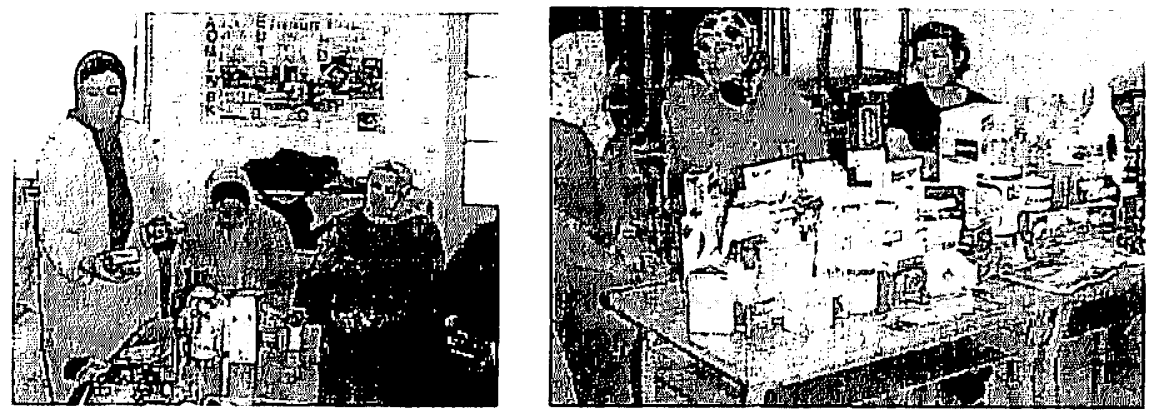
4. Después de nombrarlo, cada persona se sienta con los productos que haya cogido y escribe su nombre, copiándolo. Para ello debe discriminar de entre todo lo que la caja lleva escrito. Los adultos saben que en las etiquetas pone muchas cosas y que sólo una de ellas es el nombre del producto, por eso antes de escribirlo, se aseguran de que no se equivocan de palabra. (El adulto, al contrario que las experiencias descritas por Emilia Ferreiro con niños, no hace tentativas arriesgadas).

5. Escriben los nombres de algunos productos y se les anima a comprobar que lo han copiado bien, los que perciban el error lo corregirán.

6. La fase posterior es entender lo que se ha escrito. Deben dar a un compañero o compañera la lista que han confeccionado y éste debe coger todos los envases de esa lista. Aquí se comprueba si la lista de productos es legible y se completa la comunicación, la función de la escritura: ser comprendida por los demás.

Ejercicios con envases pueden hacerse cientos y además es un recurso barato e inacabable, tiene funcionalidad y se presenta en su soporte real lo que nos da muchas pistas acerca de lo que es.

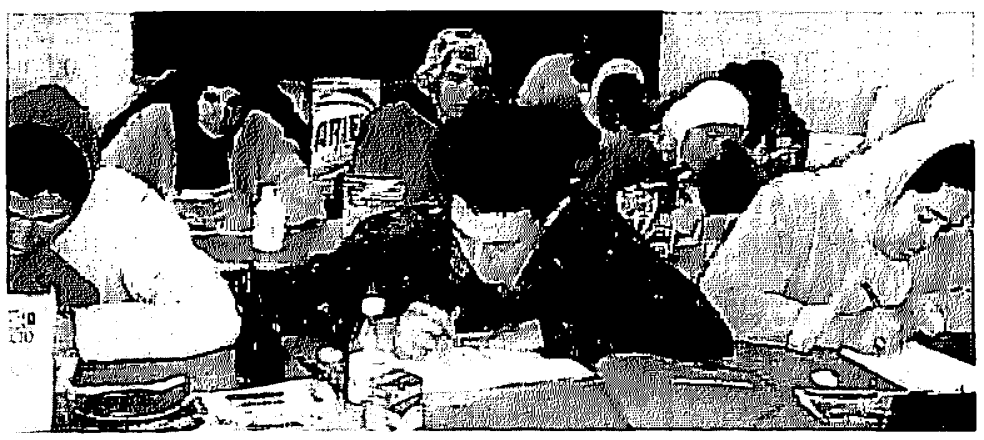

Alumnos de un curso de nivel I de la O.N.C.E a cargo de la profesora Yamila Mohamed.

\section{Dominó: imagen y palabra}

Un material de refuerzo muy útil, creado con el objetivo de generar vocabulario en castellano que sea significativo para el alumno. Se trata de utilizar palabras que en tamazight son préstamos del castellano (no todas) y luego ir pasando a otros vocabularios cuando se vaya asentando un número de vocablos cada vez mayor. Las palabras se agrupan con algún criterio: por ejemplo, productos alimenticios para elaborar una lista de la compra. Igual que se hacen estos dominós (con fotografías sacadas de folletos de supermercado y luego plastificado), puede hacerse cualquier otro material. La finalidad siempre es asociar la palabra en castellano a la imagen, en algunos casos se ha escrito en otro color la palabra en tamazight. Cumplimos dos principios que hemos de tener en cuenta: - Utilización de imágenes reales (ya vimos la importancia de esto en la parte en la que se analizan los iconos). 
- recurrir en una fase inicial a los préstamos del castellano al tamazight.

- agrupar las palabras por criterios de significado en vez de dificultad de sus sillabas.
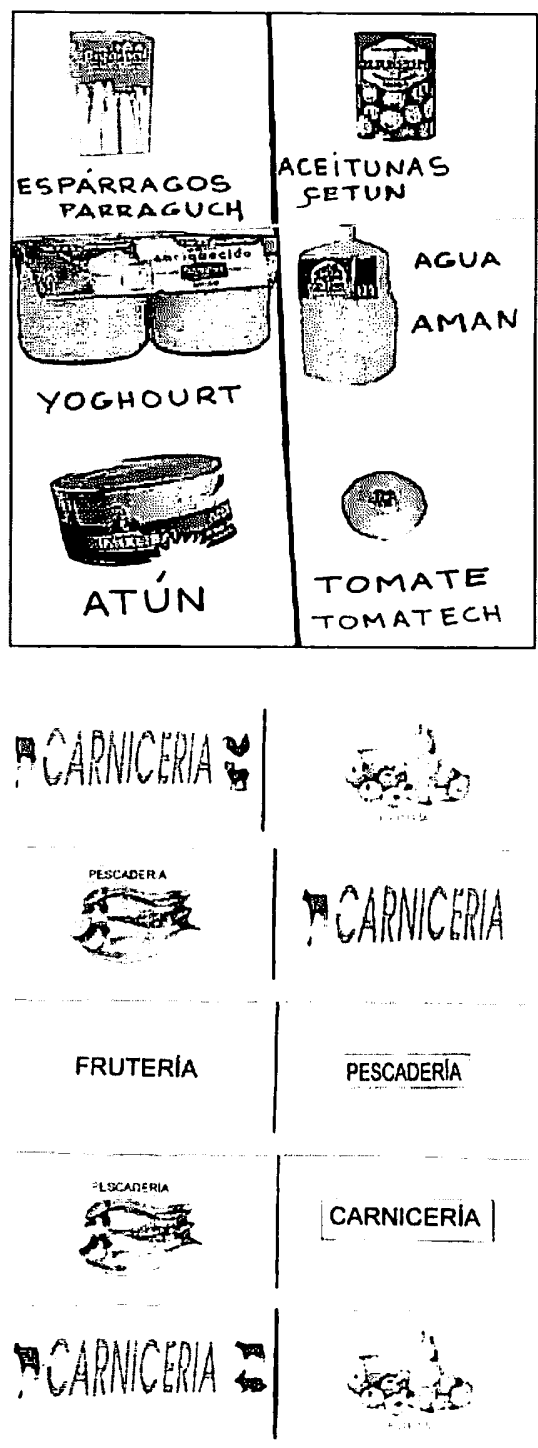

El Dominó consiste en crear piezas de cartulina divididas en dos partes, en una se coloca la imagen con la palabra y en la otra puede ir: otra imagen con otra palabra, la palabra sola, la imagen sola... se trata de ir uniendo las cartulinas igual que en un dominó, y de que la persona que lo maneje asocie palabra con imagen y en último término reconozca la palabra sola separada de su correspondiente imagen. Son ejercicios de refuerzo para realizar individualmente. 
Rutinas en el aula

Pasar lista

Se trata de utilizar como recurso oral y lectoescritor las rutinas diarias del aula. Una de esas rutinas es la de pasar lista, mucho más si es un curso subvencionado donde se controla al máximo la asistencia. Si dejamos que esta tarea la hagan los alumnos la convertimos en un recurso muy útil.

Como todas las tareas que se plantean con grupos iniciales, al principio surgen dificultades imprevistas que, una vez hecha la experiencia se van superando:

1. Elaboramos un listado a tamaño mural con los nombres de los alumnos en letras de molde grandes (sin apellidos). A aquellos alumnos/as que se llaman igual les ponemos algo que los diferencie (la inicial de su apellido, por ejemplo].

2. Como habrá alumnos que lleven un ritmo más lento y que todavía no reconocerán más que su propio nombre, los primeros días añadimos una fotografía tamaño carnet a cada uno de los nombres, así habrá personas que pasen lista sólo mirando de la foto.

3. Junto a los nombres de los alumnos se pone un cua-

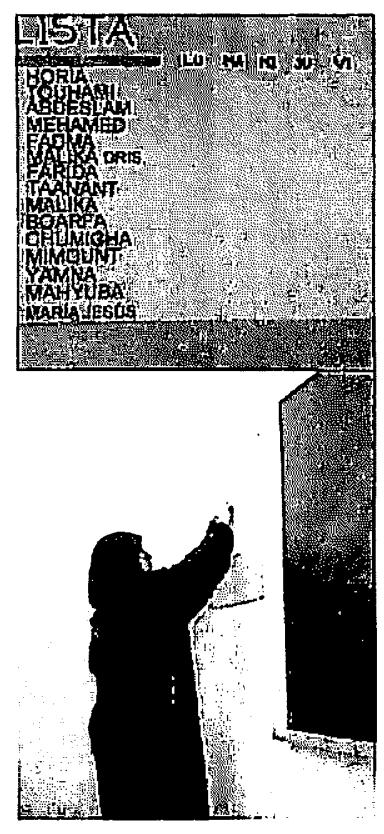

Alumna poniendo la fatta a los que no han asistido. drante con los días laborables de la semana (LUMA-MI-JU-VI] y cada día se encarga uno de colocar las cruces a los que han faltado. Otras rutinas que pueden aprovecharse en el aula son: mirar la fecha a diario en un periódico local y escribirla, consultar el cupón premiado de la O.N.C.E, comentar algunas fotos en el mismo periódico, ver la cartelera del cine, la predicción del tiempo (iconos), etc.

\section{Agenda telefónica}

Una necesidad para la persona adulta es el manejo del teléfono y también el tener una agenda telefónica con los números más importantes de su familia y amistades y también de servicio público.

Para tener una primera agenda, fotocopiamos la que se publica en el diario "Melilla Hoy", aunque retocando algunas expresiones poco habituales como:

SERVICIO DE EXTINCIÓN DE INCENDIOS que es sustituida por BOMBEROS y SERVICIO DE URGENCIAS por URGENCIAS.

Para llamar por teléfono no sólo se debe saber consultar un teléfono y llamar, sino también mantener una conversación. Por ejemplo, es vital llamar a los bomberos y ser capaz de decir la dirección a la que deben acudir, esto puede dramatizarse en el aula. Otros ejercicios prácticos son: pedir un taxi, pedir una ambulancia o llamar a la policía. 


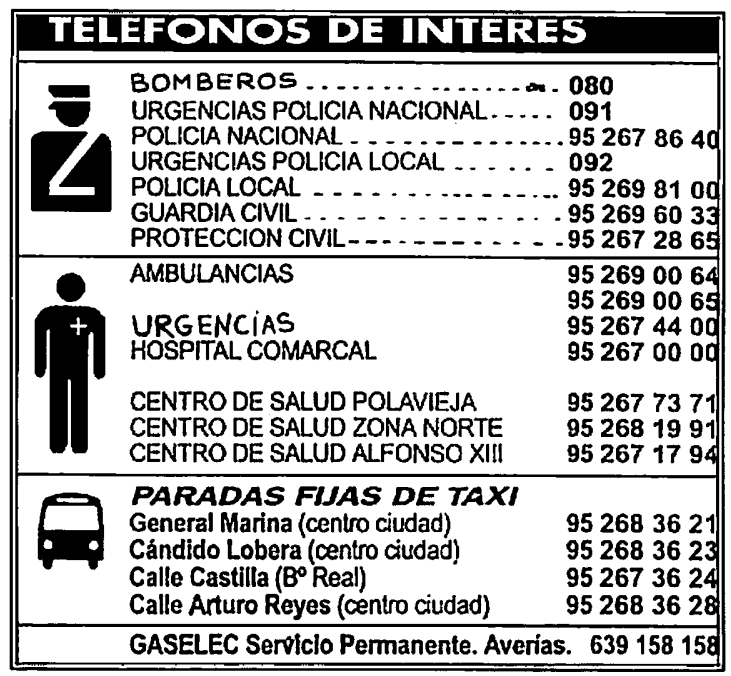

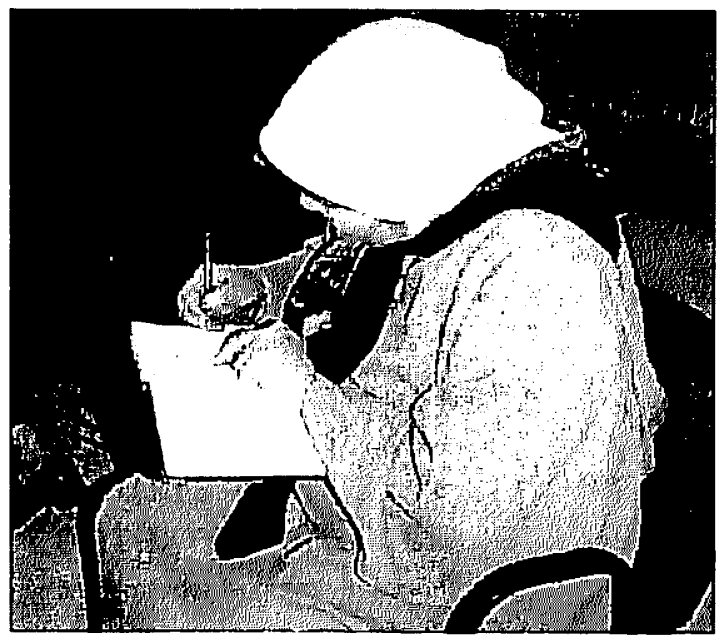

Además, los alumnos confeccionan un agenda particular con los nombres que ellos quieren incluir. Se les proporciona la agenda y se escriben los teléfonos de las personas por orden alfabético. Aquí la necesidad es diferente: deben aprender a escribir los nombres y sus teléfonos correspondiente ya que para hablar con sus amigos y familiares lo harán probablemente en tamazight. Cada actividad tiene unas necesidades orales, de escritura y lectura distintas.

La confección de una agenda particular es una actividad que puede realizarse a lo largo de todo el curso. 

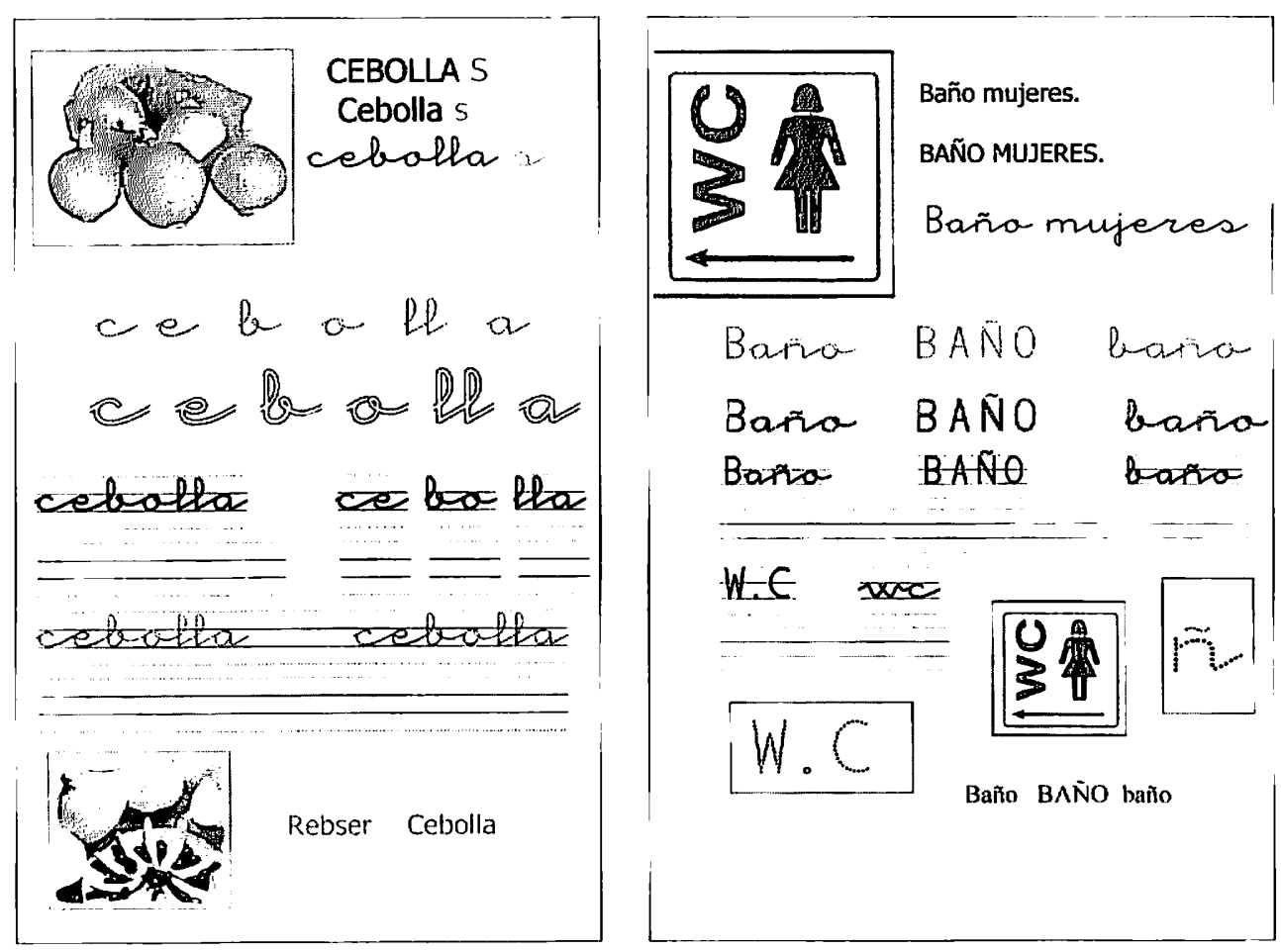
Reflexiones acerca de la enseñanza del español como lengua de segunda adquisición a personas adultas hablantes de tamazight

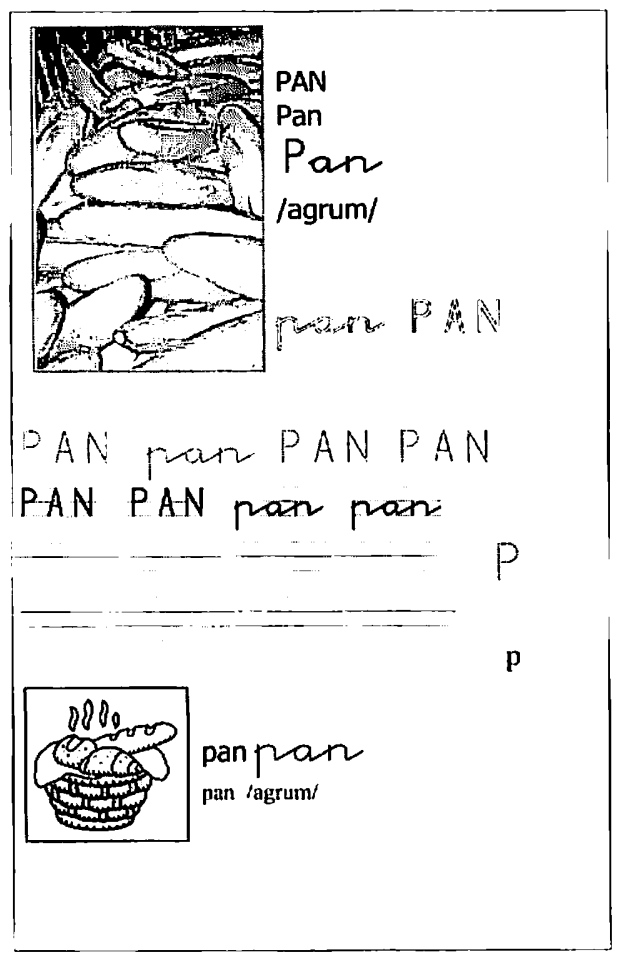

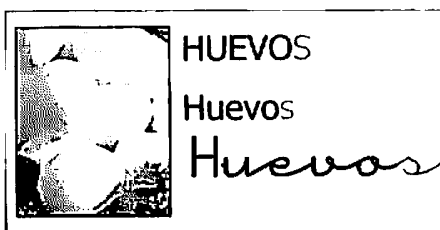

HUEVOS Hurevas HUEVOS RUEAOr Hurevos HUEVOS
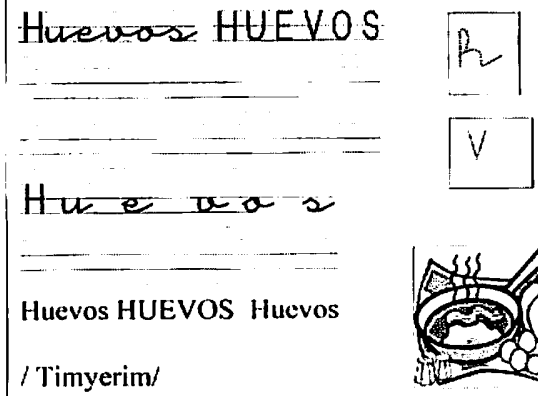

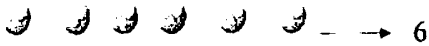

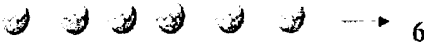

$$
\begin{aligned}
& 12 \text { HUEVOS }=1 \text { DOCENA }
\end{aligned}
$$


Ejemplo de ficha de refuerzo

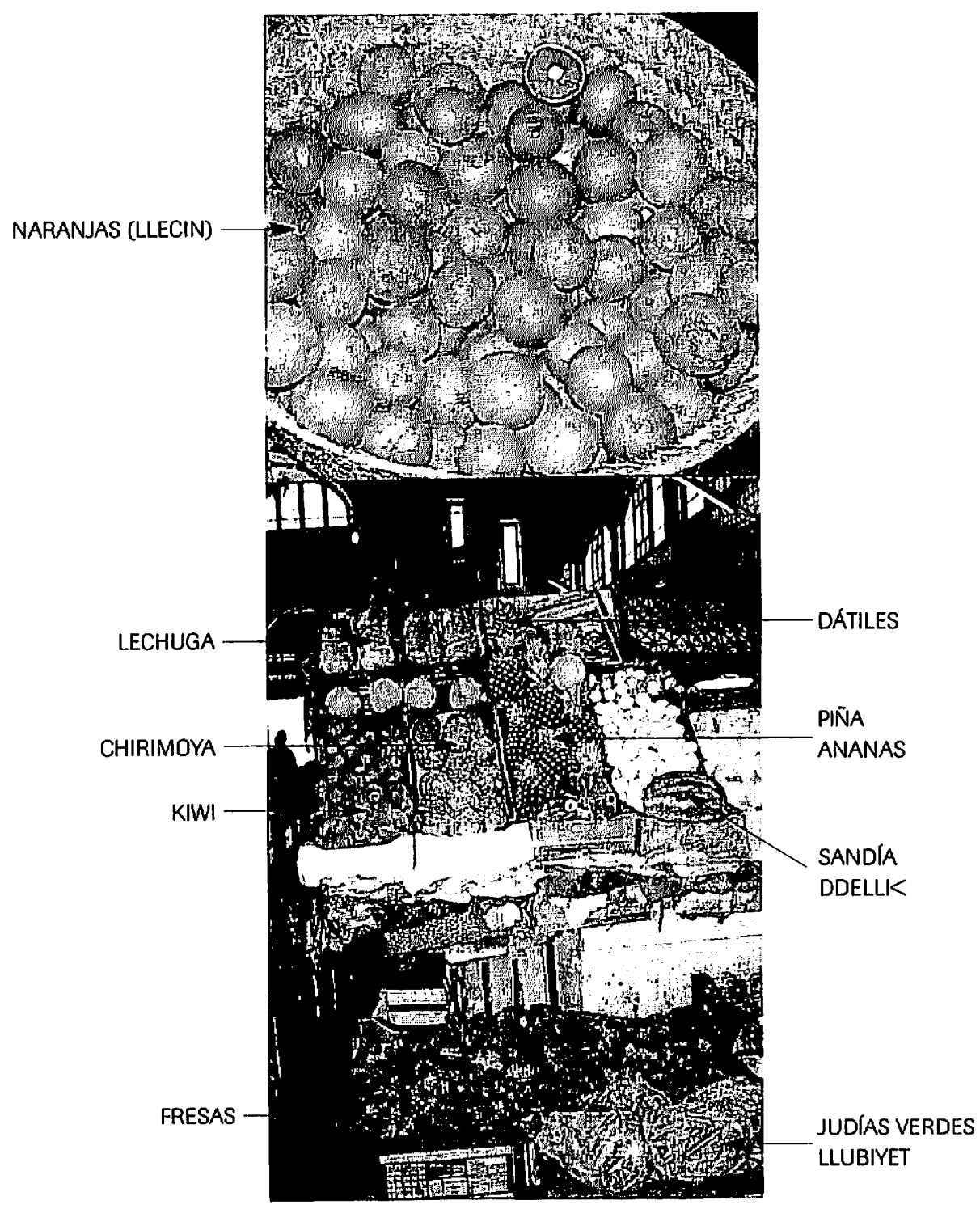


Reflexiones acerca de la enseñanza del español como lengua de segunda adquisición a personas adultas hablantes de tamazight

\section{Bibliografía}

- "Substratos y sinergias culturales". Ed. Vicente Moga y Rachid Rahá. Servicio de Publicaciones de Melilla, 2000.

- "Amazigh-tamazight. Debate abierto". Aldaba no 19. UNED.

- "Imazighen del Magreb entre Occidente y Oriente (Introducción a los Bereberes)". Ed. Rachid Raha. Granada, 94.

- "La lengua rifeña. Tutlayt Tarifit". M. Tilmatine, A. El Molghy, C. Castellanos, H. Banhakeia. Ciudad Autónoma de Melilla. Consejería de Cultura. Educación. juventud y Deporte. 1998.

- "Diccionario español-rifeño"-F. Esteban Ibáñez Madrid-1944.

- Viñeta de KÁLIKATRES (Ángel Menéndez Menéndez) expuesta en la Campaña "La Juventud se rie del racismo" organizada por La Asociación Nacional Presencia Gitana. 1996.

- "Leer y escribir con sentido" P. Carlino y D. Santana Ed. VISOR Madrid-1996.

- "Aprendiendo a escribir" Ana Teberosky. ICE-HORSARI Barcelona-1993.

- "Escribir y leer" (3 tomos)-Liuís Maruny Curto, Maribel Ministral Morillo, Manuel. Miralles Teixidó. Ed. Edelvives. Barcelona 1997.

- Aprendizaje del lenguaje escrito" procesos evolutivos e implicaciones didácticas. Liliana Tolchinsky Landsmann. ED. Antthropos. Barcelona-1993.

- "Alfabetización: Teoría y Práctica" Emilia Ferreiro. Ed. Siglo XXI. México D.F-1997.

- "Haceres, quehaceres y deshaceres" Emilia Ferreiro y colaboradores.

Libros del Quirquincho.

- "Estrategias de Lectura" Isabel Solé.

Ed. Graó. ICE Barcelona. $4^{\mathrm{a}}$ edición-1994.

- "Para darle sentido a la lectura". Frank Smith. VISOR. Madrid-1997.
- "Describir el escribir" Daniel Cassany. Ed. Graó. Barcelona-1997.

- "La selva del lenguaje" Introducción a un diccionario de los sentimientos. José Antonio Marina.

- "La casa de los Iqera'ayen" M. D Vidal Garcia. L. Abderramán, C. C Moreno. Ciudad Autónoma de Melilla. Melilla-1998.

- "Gramática de la Lengua rifeña" Sarrionandía,

P. Tánger. Misión Católica, 1905.

- "Dossier amazighs" n 1 al 6 y 14.

Rachid Raha Ahmed

Colectivo de Educación y Estudios Amazigh. Granada 1998.

- "Mujer tamazight y fronteras culturales" Varios autores. Servicio de Publicaciones de Melilla 1998.

- "Lecturas para una educación intercultural" $F$. Javier Garcla Castaño y Antolín Granados Martínez. Ed. Trotta. Valladolid 1999.

- "Aprendizaje significativo: teoria y práctica". Marco Antonio Moreira. Aprendizaje VISOR Madrid-2000.

- "Ideología y currículo"-Michael W. Apple. AKAL UNIVERSITARIA Madrid 86.

- "Lengua y Cultura de Origen: Niños marroquíes en la escuela española" Taller de Estudios Internacionales Mediterráneos. Ediciones del Oriente y del Mediterráneo. Madrid-1999.

- "Educación y bilingüismo". Miguel Siguán y William F. Mackey. Santillana/UNESCO. Aula XXI. Madrid, 1986.

- "Educación y situaciones bilingües en contextos multiculturales. Estudio de un caso: Melilla".

$M^{a}$ Carmen Mesa y Sebastián Sánchez Fernández. C.I.D.E (Centro de Investigación y Documentación Educativa) Granada 1996.

- Material inédito y apuntes del Seminario de Lengua y Cultura Tamazight de la Ciudad Autónoma de Melilla. Yafar Hassan Yahía. 